\title{
Immobilization of Proteins in Silica Gel: Biochemical and Biophysical Properties
}

\author{
Luca Ronda $^{\mathrm{a}}$, Stefano Bruno ${ }^{\mathrm{b}}$, Barbara Campanini ${ }^{\mathrm{b}}$, Andrea Mozzarelli, ${ }^{\mathrm{b}, \mathrm{fg}}$, Stefania Abbruzzetti ${ }^{\mathrm{c}, \mathrm{h}}$, Cristiano \\ Viappiani $^{\mathrm{d}, \mathrm{h}}$, Antonio Cupane ${ }^{\mathrm{e}}$, Matteo Levantino ${ }^{\mathrm{e}}$ and Stefano Bettati ${ }^{{ }^{*}, \mathrm{f}}$
}

\begin{abstract}
${ }^{a}$ Department of Neurosciences, ${ }^{b}$ Department of Pharmacy, ${ }^{c}$ Department of Biosciences, ${ }^{d}$ Department of Physics and Earth Sciences, University of Parma, Italy; ${ }^{e}$ Department of Physics and Chemistry, University of Palermo, Italy; ${ }^{f}$ National Institute of Biostructures and Biosystems, Rome, Italy; ${ }^{g}$ Institute of Biophysics, CNR, Pisa, Italy; ${ }^{h} N E S T$, Nanoscience Institute, CNR, Pisa, Italy
\end{abstract}

\begin{abstract}
The development of silica-based sol-gel techniques compatible with the retention of protein structure and function started more than 20 years ago, mainly for the design of biotechnological devices or biomedical applications. Silica gels are optically transparent, exhibit good mechanical stability, are manufactured with different geometries, and are easily separated from the reaction media. Biomolecules encapsulated in silica gel normally retain their structural and functional properties, are stabilized with respect to chemical and physical insults, and can

Stefano Bettati sometimes exhibit enhanced activity in comparison to the soluble form. This review briefly describes the chemistry of protein encapsulation within the pores of a silica gel three-dimensional network, the mechanism of interaction between the protein and the gel matrix, and its effects on protein structure, function, stability and dynamics. The main applications in the field of biosensor design are described. Special emphasis is devoted to silica gel encapsulation as a tool to selectively stabilize subsets of protein conformations for biochemical and biophysical studies, an application where silica-based encapsulation demonstrated superior performance with respect to other immobilization techniques.
\end{abstract}

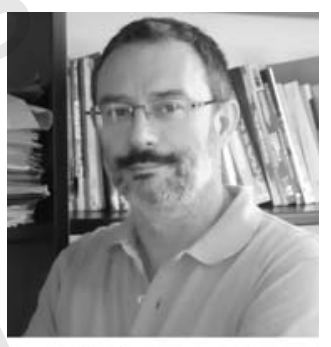

Keywords: Sol-gel, encapsulation, conformational transitions, protein dynamics, heme proteins.

\section{INTRODUCTION}

Proteins are biological macromolecules that carry out a wide range of functions in all kingdoms of life: i) enzymes react with specific substrates and catalyze anabolic and catabolic reactions; ii) antibodies selectively recognize and bind antigens; iii) carriers and receptors transport a variety of ligands through different body districts, tissues and cells, recognize specific signals and trigger interand intra-cellular signaling cascades; iv) proteins with structural and mechanical roles provide scaffolding and shape to cells and organelles; v) molecular motors are used by eukaryotic cells to transport various intracellular cargos along cytoskeleton polymers. All these functions require structural dynamics, and the fine tuning of the equilibrium among alternative structures, often separated by tiny free energy differences (Fig. 1). Indeed, as a consequence of the required flexibility, protein native state(s) are intrinsically labile, being stabilized over inactive, denatured states by only a few tens of $\mathrm{kcal} / \mathrm{mole}$. Such lability is the main challenge to overcome when trying to encapsulate proteins in organic or inorganic polymeric matrices for the biotechnological exploitation of their attractive properties of specificity and efficiency [1].

This review will focus on functional properties and applications of proteins immobilized in the pores of silica gel three-dimensional matrices, and will not cover the use of silica gel supports for surface binding of proteins, nor the expanding field of organic-modified silica gels. Encapsulation of proteins in silica gels prepared through the sol-gel method began in the 1990s [2-4]. Although there are reports indicating reversible, protocol-dependent changes in the secondary structure of some proteins and model peptides [5-7],

*Address correspondence to this author at the Department of Neurosciences, University of Parma, Parco Area delle Scienze 23/A, 43124 Parma, Italy; Tel: +390521 905502; Fax: +390521 905151; E-mail: stefano.bettati@unipr.it proteins encapsulated in silica gels normally retain their native conformation and spectroscopic properties. Function can be retained completely or partially, or even increased when the gel matrix stabilizes active conformations and/or provides a favorable environment for enzyme catalysis.

Major advantages of silica gel as a matrix for protein immobilization are [8-12]:

- relatively fast and cheap chemistry;

- mild $\mathrm{pH}$ and temperature conditions, compatible with retention of protein structure and function;

- flexible chemical protocols, allowing the use of a variety of additives and precursor molecules;

- flexible geometry of the devices, ranging from monoliths to bi- and multi-layers, powders, nano and microparticles, with variable degree of humidity (wet gels, xerogels, aerogels);

- tunable pore size; nanoporous silica gels immobilize large biomolecules while letting small molecules such as reagents or analytes to diffuse freely into the matrix $[9,13,14]$;

- optical transparency, allowing to exploit several spectroscopic techniques for the characterization of the encapsulated molecules or for biosensor applications;

- possibility of separation of the protein-doped silica matrix from the reaction medium.

Given these advantages, and the normally good retention of biological activity of the entrapped biomolecules, silica gels have been used for now more than 20 years to immobilize proteins, peptides, nucleic acids and even whole live cells for the development of biotechnological devices (bioreactors, biosensors, separation and photonic devices) $[8-10,12,13,15-18]$ or for biomedical applications (biomaterials, biosensors and systems for production, screening and controlled delivery of bioactive compounds [19-22]). Furthermore, 


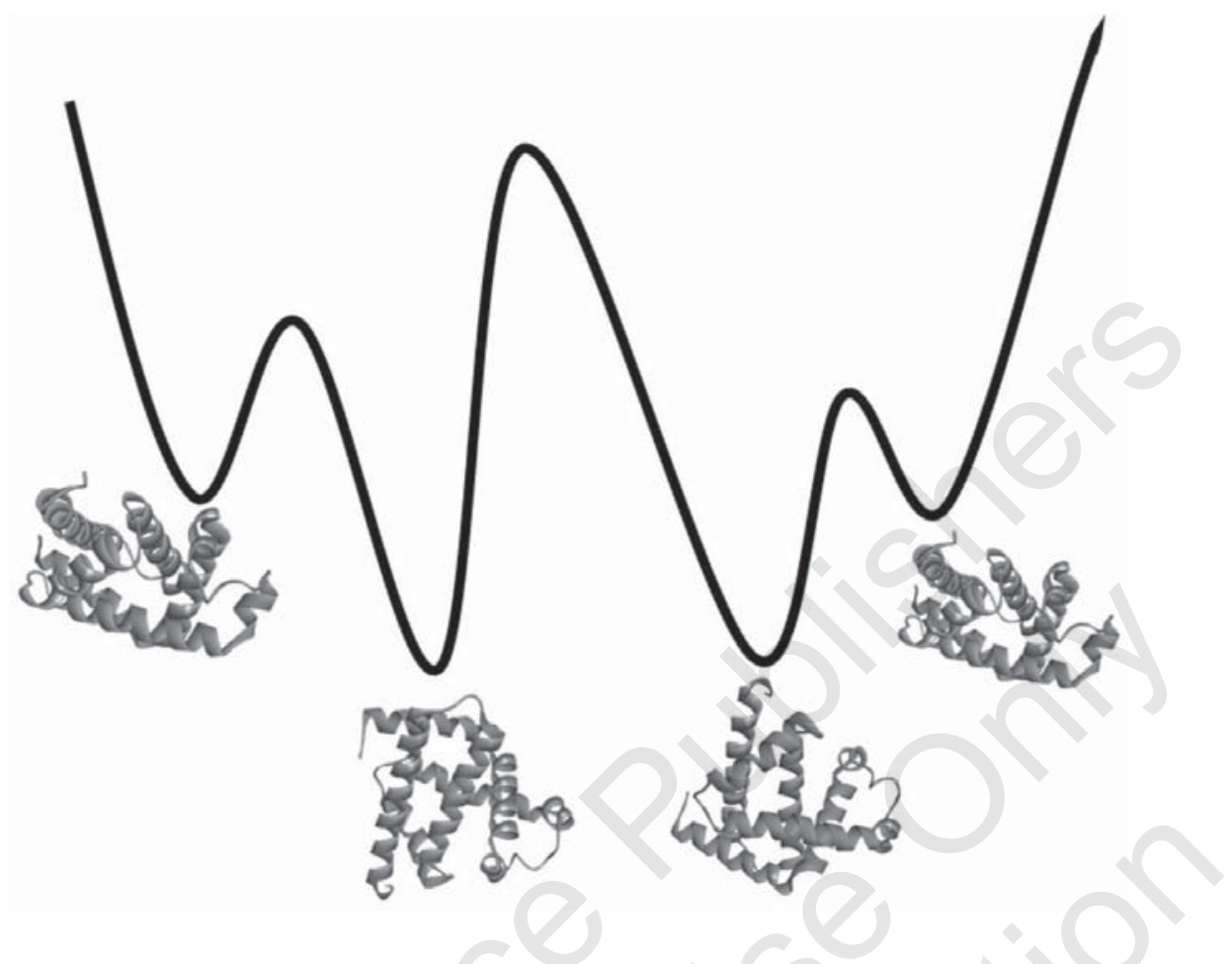

Fig. (1). Pictorial representation of a protein energy landscape, where each well corresponds to a stable conformation. The energy required to pass from one well to another is close to the thermal energy.

differently from other polymeric matrices used for protein encapsulation, silica gels have been widely exploited in biophysical studies, thanks to their optical transparency, and their capability to isolate and stabilize defined protein tertiary and quaternary states by inhibiting or decreasing the rate of conformational changes. In this review, special attention will be devoted to the latter aspect, both because it represents a unique aspect of silica gels with respect to other matrices exploited for protein immobilization, and because it is the field of much of the experimental activity in our own laboratories.

\section{PROTEIN ENCAPSULATION IN SILICA GELS}

Encapsulation in silica gels normally preserves the functional properties of biological macromolecules, such as proteins, peptides and nucleic acids, or even whole cells, thus allowing a wide range of applications. Since biomolecules cannot withstand extreme temperatures, typically needed for preparing silica glasses, the immobilization of proteins and other biological macromolecules is achieved via the sol-gel process. This technique allows for the encapsulation of biological molecules in silica-based glasses and represents a useful strategy for the preparation of inorganic and inorganic-organic hybrid materials [23]. Silica sol-gel has become an alternative to common organic polymers thanks to the simple and modular preparation protocol, the photochemical and electrochemical stability and the high optical quality. Silica sol-gels are chemically inert, hydrophilic, and exhibit improved thermal stability and mechanical strength, and reduced swelling, in comparison to other organic polymers. Moreover, biological entities are stabilized by encapsulation in a silica matrix, which creates a cage around the biomolecule protecting it from aggregation, dissociation and degradation. In the case of devices exploiting encapsulated enzymes, the catalytic activity is also strongly affected by the chemical interactions between the matrix and the protein surface. The sol-gel syn- thesis occurs in mild conditions (room temperature and atmospheric pressure). Available methods allow for the preparation of materials with different shape and configuration, from monoliths to thin films and fibers. The absence of coupling agents and the aqueous medium are conditions that favor the maintenance of biological structure and activity. In some cases, it has been demonstrated that the function of the protein encapsulated in silica gel is retained not only for molecules buried inside the pores, but also for those on the surface [24].

Common precursors for silica gel synthesis are tetraalkoxysilane and mono-, di-, and tri-alkyl alkoxysilanes such as tetraethyl orthosilicate (TEOS) and tetramethyl orthosilicate (TMOS). Redoxactive sol-gels can be synthesized using transition metal oxide solgels and/or incorporating conducting and redox components for the development of bioreactors or electrochemical biosensors [25]. In principle, most metal oxides could be used to produce gels through the sol-gel method. However, the synthesis conditions could not be compatible with the integrity of biomolecules. Particularly, in the case of transition metals alkoxides, hydrolysis and condensation steps are too fast to allow for efficient encapsulation [26].

\subsection{Protein Encapsulation Chemistry}

The sol-gel process is based on the growth of colloidal particles, also called sol, and their subsequent network (gel) formation, through the hydrolysis and condensation reactions of alkoxide monomers [9]. The sol-to-gel transition is commonly triggered by changing the $\mathrm{pH}$ of the solution reaction. Once the gel is formed, water can be eventually removed following two different procedures: 1) supercritical drying, allowing to preserve the size and the structure of the gel pores (aerogel); 2) a slow evaporation process, with a concomitant gel network collapsing (xerogel).

Silica-based glasses are typically prepared by mixing the silicon alkoxide (e.g.: TMOS or TEOS) with water in a co-solvent 
a)<smiles>[R]O[Si](O[R])(O[R])O[Si](O[R])(O[R])O[R]</smiles>

b)<smiles>[R20][Si]([R20])([R20])O[IH+]</smiles><smiles>[R]O[Si]([R20])([R])O</smiles><smiles>[R20][Si]([R20])([R20])O[Si]([R20])([R20])[R20]</smiles>

c)<smiles>[R]O[Si]([R20])([R20])O[R]</smiles>

\section{$\longrightarrow$}

$\mathrm{R}=\mathrm{CH}_{3}$ (TMOS), $\mathrm{CH}_{3} \mathrm{CH}_{2}$ (TEOS), etc.

Fig. (2). Mechanism of silica gel formation through the sol-gel method. A tetraalkoxysilane is hydrolysed to form one or more reactive silanol groups and an alcohol as a byproduct (a). Two free silanol groups condensate to give a water condensation (b) or a silanol group reacts with an alkoxysilane group to give an alcohol condensation (c).

(e.g.: ethanol). During hydrolysis (Fig. 2a) of metal alkoxides, a hydroxyl ion attacks the metal atom and the alcohol is released, leaving a reactive silanol group (Fig. 2a). During condensation of silanol groups (Fig. 2b-c), occurring during gel formation, water and/or alcohol molecules are also released. The latter can be deleterious for biomolecule stability, if not promptly removed.

Hydrolysis and condensation occur through a nucleophilic $\mathrm{SN}_{2}$ substitution on Si. Acidic, basic, or nucleophilic catalysts are commonly added to silicon alkoxides due to their low reactivity relative to other metal alkoxides [23, 27].

The sol, formed upon hydrolysis, shares properties of both real molecular solutions and particle dispersions [28]. Short-range forces such as van der Waals interactions play the main role leading the interaction between particles. In the sol-gel process the solution viscosity progressively increases, as the sol, a colloidal suspension, turns into a porous three-dimensional network.

Since the chemical control of the mechanism and kinetics of the sol-gel reactions strongly influence the composition, the properties and the morphology of the formed silica gel [23, 27, 29], reaction parameters need to be carefully characterized and tuned.

\subsubsection{Process Parameters Affecting Gel Structure}

The typical process parameters which affect structure and properties of silica gels are the $\mathrm{H}_{2} \mathrm{O}: \mathrm{Si}$ ratio, $\mathrm{pH}$, solvent and catalyst [30].

\section{$\mathrm{H}_{2} \mathrm{O}: \mathrm{Si}$ Ratio}

Water is a reagent in silicon alkoxide hydrolysis (Fig. 2a) and a product in silanol groups condensation (Fig. 2b), hence a higher $\mathrm{H}_{2} \mathrm{O}$ :Si ratio promotes the hydrolysis, while it has a more complex effect on condensation reactions. At a molar ratio $<<4$, the alcohol- producing condensation reaction is favored, whereas with a ratio $>>4$ the water forming reaction is favored.

pH

At acidic conditions, hydrolysis involves protonation of the alkoxide group, increasing its leaving group character, followed by nucleophilic attack by water; under alkaline conditions, hydrolysis implies a nucleophilic attack on the silicon atom by the hydroxide anion, forming a negatively charged five-coordinated intermediate, followed by the displacement of an alkoxide anion [23, 27]. Given these reaction mechanisms, under acidic conditions the hydrolysis rate decreases at each subsequent hydrolysis step, whereas under basic conditions each subsequent hydrolysis step becomes faster as hydrolysis and condensation proceed. The dependence on $\mathrm{pH}$ of the hydrolysis rate, which exhibits a minimum at $\mathrm{pH} 7$, indicates that the reaction can be either acid or base catalyzed [31]. Inorganic acids are considered more effective as catalysts than bases because the silanol groups forming during the reaction can neutralize basic catalysts.

The $\mathrm{pH}$ dependence of the gelling time shows the apparent condensation rate to have a maximum at intermediate $\mathrm{pH}(\sim 4.5)$ and a minimum at low $\mathrm{pH}(\sim 2.5)$. Strongly basic conditions result in nongelling systems [32].

\section{Solvents}

Solvents are classified in terms of polarity (polar and apolar) and capability to bind and release protons (protic and aprotic). Solvents which hydrogen bond to $\mathrm{OH}^{-}$or $\mathrm{H}^{+}$reduce the catalytic activity under basic and acidic conditions, respectively. In the condensation mechanism, protic solvents are expected to slow down the reaction of the base-catalyzed condensation and to promote acid- 
catalyzed condensation, while aprotic solvents show the opposite effect.

\section{Substituents on Si Center}

Hydrolysis of alkoxysilane is strictly dependent on the size of the alkoxyl groups. In fact, steric factors play the main role in determining the stability of organoxysilanes to hydrolysis, whereas the increase in the number of silanols on the silicon atom determines an increase in the condensation rate [33].

\subsubsection{Process Parameter Affecting Embedded Biological Mole- cules}

\section{pH Inside the Gel Pores}

$\mathrm{pH}$ in the pores of a silica gel, or any support matrix, has to be considered as it can influence the activity of encapsulated biological entities. In silica gels, at neutral $\mathrm{pH}$, silanol groups are negatively charged and hence the electrical double layer consists primarily of cationic buffer ions and hydrogen ions. This makes the local $\mathrm{pH}$ lower than that of the bulk solution. As a matter of fact, it has been observed that $\mathrm{pH}$ in the gel is $0.5-1$ units lower in pores than in the buffer solution [32], as also demonstrated by titration with acidbase indicators [34].

\section{Network Growth Models}

Growth models were applied to describe how hydrolysis and condensation reaction rates determine silica structure [23]. Protocols at low $\mathrm{pH}$ and low water content yield tighter gels with smaller pores, whereas protocols employing high $\mathrm{pH}$ and high water content yield more porous materials [23, 27, 35]. A separation of the hydrolysis and condensation steps through specific catalysis conditions, allows to tune the kinetics of each step.

\section{Preserving Protein Function}

Even sol-gel protocols that are performed at room temperature and that are particularly suitable for the encapsulation of biological molecules still involve the release of alcohol (Fig. 1). Furthermore, extreme $\mathrm{pH}$ conditions can be experienced during reactions, with detrimental effects on the embedded biological molecules such as protein denaturation or aggregation. Since the 1990s, Dunn and coworkers introduced modifications to the sol-gel procedure to prevent the adverse effects of $\mathrm{pH}$ and alcohol on enzyme stability [4]. Despite the optimization of sol-gel protocols, silica gel confinement is reported to promote in some cases protein denaturation For this reason, additional solutes or modified silica surfaces can be introduced to stabilize the protein [5]. Examples of stabilizers are $\mathrm{Ca}^{2+}[36,37]$, organosilanes [38, 39], polyethylene glycol (PEG) [40], graft copolymers [41-43] and charged polymers [44, 45]. Encapsulated proteins are stabilized also by the addition of small solutes such as sugars or amino acids during sol-gel processing [46, 47]. Moreover, a "biofriendly" sol-gel protocol was recently developed by creating hybrid gels from glycol-modified TEOS in the presence of $O$-2-hydroxy-3-(trimethylammonio)propyl guar gum and used for papain encapsulation [48]. Cytochrome c (cyt c) encapsulated on indium-tin oxide electrodes is able to perform direct electron transfer only when the protein is encapsulated in methyl modified silica gel [49].

More recently, the use of silica gel for the entrapment of integral membrane proteins has been considered for applications like biosensing, affinity chromatography, screening of drugs and biocatalysis $[17,50]$. Nanolipoprotein particles were demonstrated to be very well preserved in terms of molecular structure upon silica gel entrapment [51].

\section{Modulating Protein Function}

The sol-gel chemistry allows fine tuning of the chemical and physical properties of the matrix by modulating the preparation protocol. This, in turn, can allow to adjust the dynamic and functional properties of encapsulated proteins. As an example, the activity of encapsulated acetylcolinesterase was optimized by tuning the microenvironment through the modulation of TEOS: $\mathrm{H}_{2} \mathrm{O}$ ratio and catalyst concentration [52]. The addition of $\mathrm{Ca}^{2+}$ during the encapsulation of two mutants of oncomodulin, a $\mathrm{Ca}^{2+}$ binding protein, strongly affected their stability [53]. A fine modulation of the encapsulation protocol allows to selectively isolate quaternary and tertiary states of $\mathrm{Hb}$, accompanied by a change in the functional properties [54].

\section{EFFECT OF SILICA GEL ENCAPSULATION ON THERMODYNAMIC STABILITY AND CONFORMA- TIONAL EQUILIBRIA}

With a few exceptions $[55,56]$, encapsulation of proteins in nanoporous silica gels normally produces an increased stability with respect to thermal and chemical insults, or long-term storage [9]. At the same time, encapsulation allows to selectively stabilize specific subsets of protein conformations, that, depending on encapsulation conditions and the protein system, can either reflect the "natural" distribution of species under defined solution conditions $[57,58]$, or an artificially biased population (e.g., the highly reactive conformation of an enzyme encapsulated as a biocatalyst or bioreactor [59]).

The effect of encapsulation on thermodynamic stability and conformational equilibria can be rationalized describing protein dynamics by means of a complex, multidimensional energy landscape $[60,61]$. Hierarchically structured free energy minima represent protein conformations: the deeper the free energy minimum, the more stable the single chemical species (Fig. 1). The rate of small or large scale conformational transitions will depend on the height of the barrier between adjacent minima. According to this description, silica gel encapsulation could in principle affect just the height of kinetic barriers (which would produce a slowing down of conformational relaxations, without affecting equilibrium populations), and/or the relative depth of energy minima, thus perturbing the relative stability of alternative conformations.

As for the mechanisms by which encapsulation can affect thermodynamic stability and relaxation rates, these include steric constraints, confinement effects, pore-protein electrostatic interactions, altered microviscosity and water structure in the proximity of the pore walls. The templating effect of the embedded biomolecules during gel polymerization could explain the formation of pores that fit the size and shape of the encapsulated molecules; this would pose steric constraints to highly expanded denatured states or unfolding transition states, resulting in thermodynamic stabilization of native states and faster folding rates [62]. Caging and excluded volume effects on polymer dynamics and the relevance for the stability of encapsulated proteins have been the subject of a large theoretical, computational and experimental effort in recent years [6274]. Electrostatic interactions between charged or polar amino acid side chains and the pore surface, that is negatively charged at nearphysiological $\mathrm{pH}$ (the isoelectric point can be as low as 2.1 [75]), could also be a factor affecting stability $[76,77]$. Water structure perturbation induced by the polarity of pore surface, and its effects on apparent viscosity, and solvent and solutes activity in silica gels, will be discussed in Section 4. 


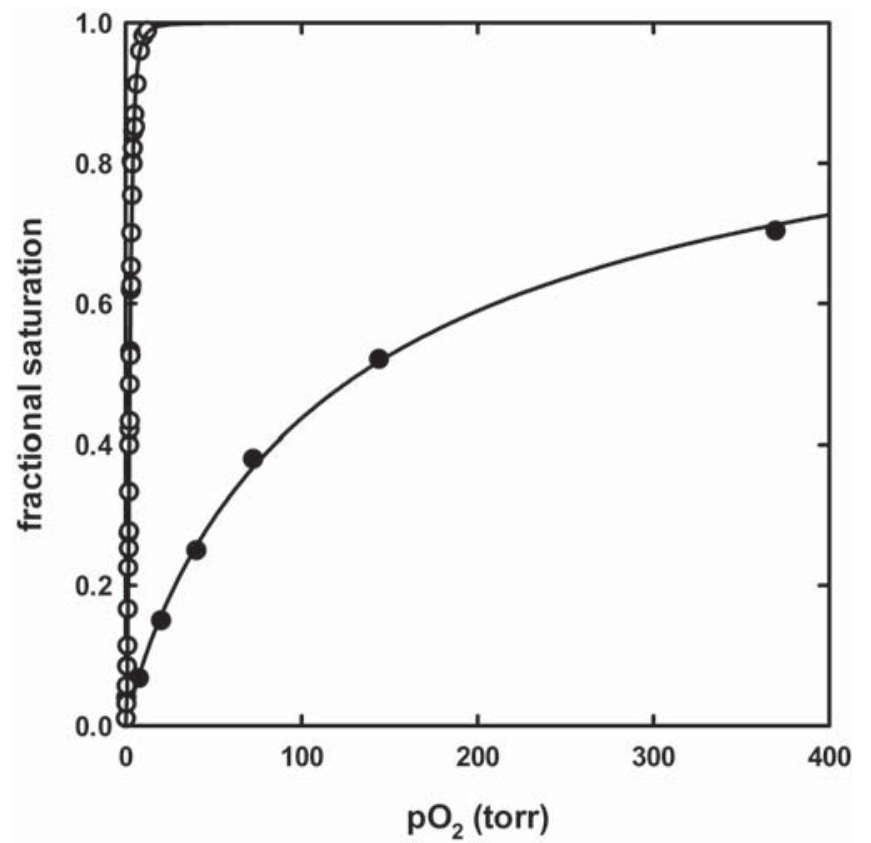

Fig. (3). Closed circles: oxygen binding curve for $\mathrm{HbA}$ encapsulated in silica gel in $100 \mathrm{mM}$ HEPES, $1 \mathrm{mM}$ EDTA, $\mathrm{pH} 7,15^{\circ} \mathrm{C}$, in the presence of the negative allosteric effectors inositol hexaphosphate $(10 \mathrm{mM})$, bezafibrate $(2 \mathrm{mM})$, and chloride $(200 \mathrm{mM})$ [58]. Data fit to a hyperbolic binding function yields a p50 (the oxygen pressure at half saturation) of $133.1 \pm 3.1$ torr and a Hill coefficient of $0.89 \pm 0.02$, indicating a non-cooperative binding in the $\mathrm{T}$ state. Oxygen affinity overlaps with that obtained in $\mathrm{T}$ state $\mathrm{Hb}$ crystals $[218,219]$, and with $\mathrm{K}_{1}$ (the affinity constant for binding of the first oxygen molecule to the $\mathrm{Hb}$ tetramer) obtained in solution in the same experimental conditions [148]. Open circles: the oxygen binding curve for $\mathrm{HbA}$ in solution in $100 \mathrm{mM}$ HEPES, $1 \mathrm{mM}$ EDTA, pH $7,15^{\circ} \mathrm{C}$ is shown for comparison $(\mathrm{p} 50=2.29 \pm 0.03$ torr, Hill coefficient $=2.54 \pm 0.10)[54]$.

In the last two decades, several reports have been published dealing with silica gel encapsulation as a means to achieve global thermodynamic stabilization and selection of specific protein conformations for biotechnological applications, and the field has been extensively reviewed $[9,15,50,78,79]$. Here, we will focus on a few case studies, some of which from our own laboratories, where the selective stabilization of protein conformers has been exploited to make them accessible to biochemical and biophysical investigation.

\subsection{Heme Proteins}

The possibility provided by silica gel encapsulation to reduce the rate of conformational changes by orders of magnitude, increasing the kinetic separation of tertiary and quaternary relaxations [57, $58,80-92]$, has been extensively exploited by several groups to make accessible to spectroscopic investigation species that are normally poorly populated, or metastable on the time scale of solution experiments. Not surprisingly, many of these studies concern hemoglobin $(\mathrm{Hb})$, myoglobin and other heme binding proteins, since the availability of a sensitive, intrinsic chromophoric signal allowed to achieve an unprecedented level of detail in the comprehension of structure-dynamic-function relationships. For this same reason, reports on heme-binding globins dominate the literature on protein dynamics in silica gels, as will be evident from Section 4 .

Stability of cyt $\mathrm{c}$ in silica gels was the subject of more than one investigation. Electronic and resonance Raman spectra of the ferric form of horse heart cyt $\mathrm{c}$ indicated stabilization with respect to acidic conditions, but not against chemical denaturation [93]. Opposite results were retrieved in other investigations, reporting increased stability towards chemical unfolding [74, 94]. The dramatic slowing down of the refolding rate in silica gel (up to several days) was exploited to investigate the folding pathway of cyt $\mathrm{c}$ by absorbance, fluorescence and circular dichroism spectroscopy [95]. The results support a stepwise folding mechanism occurring through a series of intermediates, partly corresponding to those observed in aqueous solution. Very recently, such studies were extended to a characterization of early folding events, chain collapse and secondary structure formation leading to partially folded intermediates, for cyt $\mathrm{c}$ and four other globular proteins: equine beta-lactoglobulin, human tear lipocalin, bovine alpha-lactalbumin, and hen egg lysozyme [96].

Hemoglobin and myoglobin were also used as test molecules to investigate the effects of encapsulation on protein stability and folding [71, 97-99]. However, the most striking result about $\mathrm{Hb}$ encapsulated in silica gels is the perfect conservation of equilibrium oxygen binding properties observed in solution under comparable conditions [54, 57, 58, 82, 100, 101] (Fig. 3) [218, 219], which legitimates the exploitation of this system in kinetic experiments aiming to test theoretical models of $\mathrm{Hb}$ allosteric regulation (see Section 4).

\subsection{Green Fluorescent Protein}

When studying protein dynamics and conformational equilibria in vitro, it should be considered that caging effects in the pores of the silica gel matrix might help mimic crowding and confinement experienced in vivo by proteins $[66,102,103]$ much better than the diluted solution normally used for biochemical and biophysical investigations [9, 46, 65, 98, 104-107]. Silica gel encapsulation was exploited to investigate caging effects on the unfolding mechanism of a highly fluorescent variant of Aequorea victoria Green Fluorescent Protein (GFP), GFPmut2 (S65A, V68L, S72A GFP) [108]. After preliminary studies demonstrating that encapsulated GFPmut2 maintains structural and dynamic properties, as shown by $\mathrm{pH}-\mathrm{dependent}$ absorption, fluorescence and fluorescence anisotropy [109], the kinetics and thermodynamics of unfolding induced by guanidinium chloride were characterized by several spectroscopic techniques $[106,110]$. Encapsulation was shown to stabilize [106, 111] a measurable population of molecules endowed with a different conformation, and a different thermodynamic stability, with respect to the dominant species in solution, despite indistinguishable spectroscopic features. Interestingly, the unfolding rate was scarcely affected by encapsulation, but its dependence on denaturant concentration (a measure of the change in solvent-exposed protein surface upon denaturation [112]) was reduced, consistent with restrictions posed by the gel pores to the expansion of denatured and transition states. The same approach was later applied to characterize the effect of a single amino acid mutation (H148G GFPmut2) on unfolding equilibrium and kinetics [107]. Once again, encapsulation allowed to unveil details of the unfolding mechanism that previously went undetected in solution studies.

The intrinsic fluorescence and good photo-stability of GFPmut2 allowed to exploit encapsulation for single-molecule imaging by confocal spectroscopy [109, 113]. This posed the basis for future single-molecule folding experiments $[111,114]$, that demonstrated the existence of a discrete number of protein sub-states (a not so obvious experimental observation, at room temperature) and folding and unfolding pathways. Indeed, single molecule experiments are the only way to fully capture the complexity of protein conformation and dynamics, that average out in ensemble experiments. 
Immobilization is often required to follow complete dynamic trajectories on the same molecule. The experiments on GFPmut 2 demonstrate the potential of silica gel as an immobilization matrix for single molecule spectroscopy and microscopy.

Small angle neutron scattering studies were performed on a deuterated GFP encapsulated in silica gel to investigate differences in the structural properties of doped and undoped sol-gel matrices, and the quaternary structure of the entrapped protein [115].

\subsection{Allosteric Enzymes}

Aspartate transcarbamoylase (ATCase) is a classic textbook example of an enzyme regulated by cooperative binding of the substrate, L-aspartate, and by negative and positive heterotropic allosteric effectors (feedback control) $[116,117]$. The enzyme catalyses the first step of pyrimidine biosynthesis and contains two catalytic trimers carrying the active sites and three regulatory dimers to which nucleotide effectors bind. West and Kantrowitz reported $\mathrm{R}$ and $\mathrm{T}$ state reaction kinetics and the quaternary relaxation rate of gel-encapsulated, pyrene-labeled ATCase [118]. The encapsulated enzyme maintains catalytic competence, with a maximal activity about halved with respect to solution. However, the aspartate concentration at half-maximal velocity was significantly reduced, and hyperbolic saturation corves indicated loss of homotropic cooperativity. In addition, fluorescence spectra of the pyrene-labeled ATCase, that are sensitive to changes in the quaternary structure, demonstrated that the enzyme encapsulated as $\mathrm{T}$ had emission spectra very similar to the $\mathrm{R}$ state control after rinsing out negative heterotropic effectors. This unexpected result was explained assuming that in the absence of ligands an equilibrium distribution of quaternary states, with $\mathrm{R}$ largely prevailing over $\mathrm{T}$, becomes frozen upon gel encapsulation, but could also be interpreted in terms of effectordependent tertiary equilibrium, in the absence of quaternary relaxation. The quaternary relaxation rate was reported to be approximately $10^{5}$ fold slower than in solution (a slowing factor surprisingly similar to that found for $\mathrm{Hb}[58,80])$. The authors made the interesting statement that "It should also be possible to determine if the allosteric effectors...have regulatory effects on the isolated $T$ and $R$ allosteric states" [118], which would be inconsistent with MWC. These statements are still awaiting for experimental tests.

Fructose-1,6-bisphosphatase is a homotetrameric enzyme. Binding of the allosteric ligand AMP induces quaternary conformational changes ( $\mathrm{R}$ to $\mathrm{T}$ transition) that completely inhibit the enzyme. In silica gel [119], the enzyme encapsulated in the $\mathrm{R}$ state never became completely inactivated after addition of AMP, and AMP inhibition was no longer cooperative, indicating that both tertiary and quaternary conformational changes are essential for regulation. Indeed, removal of AMP from T-state gels restores activity with a slow (hours) and biphasic process.

Glutamate dehydrogenase (GDH) is a hexameric allosteric enzyme. GDH is catalytically active in silica gel [120]. The $\mathrm{K}_{\mathrm{M}}$ for substrate is similar to solution, while the apparent $\mathrm{v}_{\max }$ is 40 -fold less. This is not necessarily due to a homogeneously reduced catalytic efficiency of the enzyme, since GDH was encapsulated in the absence of substrate, and the results might reflect a minor fraction of molecules in a fully active conformation. Consistently, reaction kinetics are Michaelis -Menten in the gel, but they show an initial delay period of several minutes that could correspond to the buildup of a population of active molecules upon tertiary and/or quaternary relaxations following ligand binding. Allosteric effectors were reported to have an effect in the gel, but no quantitative result was shown.

Glucosamine-6-phosphate deaminase degrades glucosamine 6phosphate to fructose 6-phosphate and ammonia. The enzyme is allosterically activated by $\mathrm{N}$-acetylglucosamine 6-phosphate, regulating its distribution between a highly active quaternary $\mathrm{R}$ state and a less active $T$ state. By encapsulating the enzyme either in the $T$ or in the $\mathrm{R}$ state, it was possible to investigate the functional relevance of ligand-associated tertiary structural changes [121]. Results were interpreted on the basis of the known crystallographic structures and in the frame of the tertiary two-state allosteric model of Eaton and coworkers $[58,85,122]$, assuming an equilibrium of $t$ and $r$ tertiary conformations, within each quaternary state, regulated by allosteric effectors.

\section{PROTEIN DYNAMICS IN SILICA GELS}

Thermodynamically unstable protein states are often difficult to investigate due to their elusive and transient nature. An effective method to trap unstable states is to embed proteins inside the nanopores of silica gels. The confined environment of the silica gel exerts on the macromolecules forces, which may prevent large scale, slow motions, but also hinder specific dynamics occurring on a more local and faster time scale. Motions can be selectively slowed down by the gel matrix thus impeding quaternary and/or tertiary conformational changes, which are necessary for the reactions to proceed, leading to sizeable population of otherwise difficult to detect states. In the following, we will review first the effect of silica gel encapsulation on protein large scale conformational changes. Then, we will show how different encapsulation protocols (involving the use of high viscosity cosolvents such as glycerol) allow modulating tertiary structural relaxations and ligand migration within the encapsulated protein. Finally, the effects of silica gel encapsulation on the coupling between protein and solvent dynamics will be shortly reviewed.

\subsection{Trapping Reaction Intermediates: Inhibition of Conforma- tional Changes}

Encapsulation of proteins in silica gel matrices exerts a templating effect on the structures that proteins can adopt. In particular, transition between protein conformations that require large scale conformational changes can be inhibited or greatly slowed down by direct interaction of the embedding gel matrix with the encapsulated proteins and/or by affecting the dynamics of the protein hydration shell. These effects have been used to investigate the dynamic properties of protein intermediate states that are not easily accessible in aqueous solutions, as in the case of human $\mathrm{Hb}$ quaternary transition. $\mathrm{Hb}$ is a tetrameric protein that has long served as a prototypical model system for our understanding of allosteric mechanisms [123]. In solution, $\mathrm{Hb}$ undergoes a quaternary transition following ligand release with a timescale of $\sim 1 \mu \mathrm{s}[124,125]$. This transition can be significantly slowed down by encapsulating $\mathrm{Hb}$ in silica gels [82]. The low affinity $\mathrm{T}$-state and the high affinity Rstate of $\mathrm{Hb}$ can be trapped by encapsulating $\mathrm{Hb}$ either as fully deoxygenated or fully oxygenated molecules, respectively $[57,82,83$, 100]. Indeed, non-cooperative oxygen binding is observed both when $\mathrm{Hb}$ is encapsulated in the high-affinity $\mathrm{R}$ state or in the lowaffinity $\mathrm{T}$ state $[57,58,82,83,85,100]$ (Fig. 3). In the case of $\mathrm{T}$ state encapsulated $\mathrm{Hb}$ allosteric effects have also been evidenced $[57,58]$. Monitoring the changes in the optical or resonance Raman spectra of R-state oxy-Hb gels after complete removal of oxygen demonstrated that the $\mathrm{R} \rightarrow \mathrm{T}$ transition for the fully unliganded $\mathrm{Hb}$ 
can be slowed down by up to 10 orders of magnitude $[58,80,83$, 92, 126-128]. Thus, the $\mathrm{R} \rightarrow \mathrm{T}$ transition is not prevented by the gel matrix, rather slowed down by several orders of magnitude so that intermediate short lived $\mathrm{Hb}$ states, that are unstable in aqueous solutions, can be investigated with conventional spectroscopic techniques.

Since the quaternary structural change of encapsulated $\mathrm{Hb}$ is greatly slowed down, tertiary intermediate states along the $\mathrm{R} \rightarrow \mathrm{T}$ transition could be observed by conventional spectroscopic methods such as UV resonance Raman spectroscopy [86, 89, 90]. In particular, it has been shown that after photolysis of $\mathrm{HbCO}$ encapsulated in the $\mathrm{T}$ state, both the $\mathrm{E}$ and $\mathrm{F}$ helices assume intermediate positions with respect to those that characterize the $\mathrm{Hb}$ equilibrium states. Moreover, ligand rebinding kinetics of $\mathrm{CO}$ to encapsulated $\mathrm{Hb}$ were measured in flash photolysis experiments both at room [58, 87, 89, 90, 127, 129-132] and cryogenic temperatures [88]. Inhibition of the quaternary transition allowed to study $\mathrm{CO}$ rebinding kinetics to pure $\mathrm{T}$ and $\mathrm{R}$ states. $\mathrm{CO}$ rebinding kinetics to the pure quaternary $\mathrm{R}$ state was measured on $\mathrm{Hb}$ gels where the protein was immobilized in its carboxy state, since rebinding is complete on a time scale which is much faster than the quaternary transition to deoxy $\mathrm{T}$ [ 87 , 127]. The progress curve is characterized by a large geminate recombination amounting to about $50 \%$ of the signal, and a single phase bimolecular rebinding. $\mathrm{CO}$ binding to $\mathrm{T}$ state $\mathrm{Hb}$ was determined by studying deoxy-Hb gels saturated with $\mathrm{CO}$ before any quaternary transition occurred [58, 89, 127]. Experiments afforded very different results depending on whether deoxy-Hb gels were prepared in the presence or absence of saturating allosteric effectors.

Immobilization of $\mathrm{T}$ state $\mathrm{Hb}$ in the presence of saturating allosteric effectors $\left(\mathrm{T}^{+}\right.$gels) results in negligible geminate recombination followed by a single bimolecular rebinding phase [58, 127]. When $\mathrm{T}$ state $\mathrm{Hb}$ is encapsulated in the absence of allosteric effectors $\left(\mathrm{T}^{-}\right)$geminate recombination is detected followed by a biphasic bimolecular rebinding, with characteristics of rebinding to $\mathrm{R}$ and $\mathrm{T}^{+}$ states $[58,89,133,134]$. This remarkable finding demonstrates that within the quaternary $\mathrm{T}$ state, a significant fraction of subunits behaves as R, and was interpreted on the basis of-the tertiary two-state (TTS) model $[122,135]$ as arising from a mixed population of $t$ and $r$ subunits. Contrary to what happens in $\mathrm{T}^{+}$gels, where the allosteric effectors completely inhibit any tertiary switch induced by CO ligation, in $\mathrm{T}^{-}$gels tertiary equilibrium can be reached much earlier. Since quaternary states like $\mathrm{T}$-state $\mathrm{CO}-\mathrm{Hb}$ are not completely locked into the unstable states, the time evolution of the rebinding kinetics after CO saturation can be exploited to obtain an independent estimate of the R-T quaternary transition rate. Ronda et al. followed the $\mathrm{CO}$ rebinding kinetics after laser photolysis for a few days after $\mathrm{CO}$ saturation of the $\mathrm{T}^{+}$and $\mathrm{T}^{-} \mathrm{Hb}$ gels [80]. By following the amplitude of the geminate phase and the fractions of fast and slow bimolecular phases it was possible to conclude that the time constant of the $\mathrm{R} \rightarrow \mathrm{T}$ relaxation for $\mathrm{T}^{+}$gels is on the order of two days.

Using a cw laser photolysis scheme, Eaton and coworkers recently demonstrated that a tertiary $t$ conformation can be identified in deoxy R, with functional properties comparable to those of deoxy $\mathrm{T}$ subunits [85]. The deoxy $\mathrm{R}$ species is obtained by photodissociating $\mathrm{HbCO}$ gels with a cw laser for a long enough time span to allow tertiary, but not quaternary relaxation. Rapidly switching off the laser allows to measure $\mathrm{CO}$ rebinding. When the photodissociation time is increased, a slow rebinding phase is observed, whose amplitude increases to nearly $20 \%$, with a highly stretched exponential character. A small increase in bimolecular rate with exposure time is observed, and this rate asymptotically approaches the same value of the slow rebinding phase measured for the $T$ quaternary structure. When $\mathrm{R}$ gels are prepared in the presence of saturating allosteric effectors $\left(\mathrm{R}^{+}\right.$gels), the amplitude of the slow rebinding phase increases much faster and levels off at nearly 0.5 .

The observed appearance of a slow rebinding phase could be related with formation of the quaternary $\mathrm{T}$ state after photodissociation. Spiro and coworkers found that $T$ quaternary structure markers do not appear in the resonance Raman spectra for about 5 days at 22 ${ }^{\circ} \mathrm{C}$, which is orders of magnitude longer than the longest time of $1,000 \mathrm{~s}$ used in the continuous photolysis experiments $[128,136]$. Additionally, since the Raman experiments were carried out at complete deoxygenation, the observed $\mathrm{R} \rightarrow \mathrm{T}$ rate is higher than the one observed at partial photolysis, as occurs in the continuous photolysis experiments. At the maximum photolysis levels of $13 \%$ only doubly liganded tetramers are present $(\sim 30 \%$ of the deoxyhemes) that can switch from $\mathrm{R}$ to $\mathrm{T}$ at equilibrium, which occurs in solution at a 10 - to 40 -fold slower rate [122]. The above arguments rule out any possible contribution of quaternary $\mathrm{R} \rightarrow \mathrm{T}$ transition in the appearance of the slow rebinding species in the continuous photolysis experiment.

\subsection{Trapping Reaction Intermediates: Tertiary Relaxations and Ligand Migration}

Silica gel entrapment has proved to be able also to modulate protein tertiary relaxations and therefore it is a valuable tool for investigating processes such as ligand migration through protein cavities, where incoming or outgoing ligands are temporarily docked into elusive states. This has been mostly exploited in ligand rebinding studies after laser photodissociation of diatomic gases from their complexes with hemeproteins. Owing to the reduced mobility of the polypeptide chain, the probability of escaping to the surrounding solvent for the photodissociated ligand is decreased, while the competitive process of diffusion to internal sites is favoured. The use of viscogenic cosolvents that increase the overall viscosity has allowed to further enhance the population of these reaction intermediates, thus improving sensitivity to migration reactions. Under extreme solvent conditions such as those encountered when protein gels are soaked in pure glycerol, the gel matrix prevents ligand escape to the solvent and therefore bimolecular rebinding. In these conditions, rebinding of ligands from inside the protein (geminate rebinding) is greatly enhanced. Therefore, ligand migration and structural relaxations following photodissociation become detectable at near room temperature and appear as multiple kinetic phases in the geminate recombination. This approach has been applied to gain insight into kinetics of ligand migration for several $\mathrm{Hbs}$, including vertebrate globins, bacterial and archaea Hbs, and non symbiotic plant $\mathrm{Hbs}$

Geminate recombination is often enhanced in human $\mathrm{Hb}$ gels, especially when viscogenic cosolvents are added [87]. By inhibiting ligand escape to the solvent, this promotes migration to internal cavities and increases the sensitivity of the binding progress curves to intramolecular processes [133, 134, 137, 138]. Several cases were reported where the simple gel entrapment is not enough to increase substantially geminate rebinding. For instance, in the case of myoglobin $(\mathrm{Mb})$, the simple confinement within the gel pores leads simply to a slightly increased probability of rebinding, but it is difficult to recognize in the extended nature of the geminate rebinding reaction the peculiar features of rebinding from multiple sites $[90,127,139]$. When glycerol is added to the solution where 


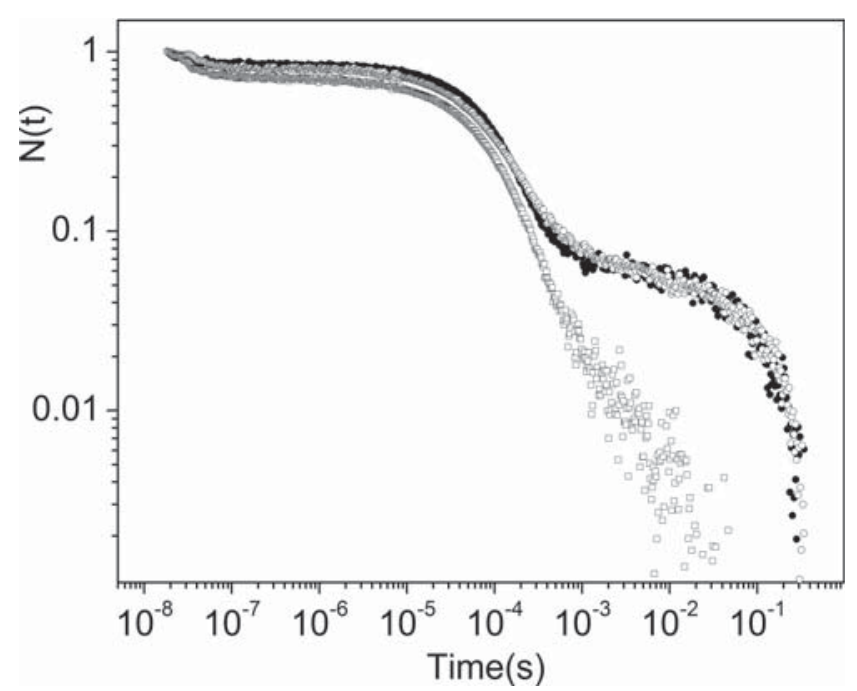

Fig. (4). Comparison between the $\mathrm{CO}$ rebinding kinetics to Cygb solutions (filled circles), COCygb gels (open squares, Cygb was embedded in the gel as COCygb) and $\mathrm{Cygb}+\mathrm{CO}$ gels (open circles, Cygb was embedded in the gel as deoxy Cygb and $\mathrm{CO}$ was added after the gel was formed). $\mathrm{T}=40^{\circ} \mathrm{C}$, $1 \mathrm{~atm}$ CO. Data from [162].

the $\mathrm{Mb}$ gel is immersed, at least one additional kinetic phase pops out, showing that the extended nature of the geminate phase is consistent with the presence of a reaction intermediate, acting as a kinetic trap [90, 129, 131, 140].

Gel encapsulation and bulk viscosity have profound effects on the exchange of ligands between the protein matrix and the solvent. Good examples to illustrate this concept are provided by non symbiotic plant hemoglobins (nsHb) [141, 142], neuroglobin ( $\mathrm{Ngb}$ ) $[143,144]$ and cytoglobin (Cygb) [145, 146]. These Hbs are collectively termed hexacoordinate $\mathrm{Hbs}$ because in the absence of hexogenous diatomic ligands, Fe coordination is completed by the distal His residue [147].

In the case of the type I non symbiotic $\mathrm{Hb}$ from Arabidopsis thaliana (AHb1), the small amplitude of geminate rebinding [148] is only slightly, if at all, increased by gel immobilization. When glycerol is added to the solution where the protein gel is soaked, a progressively increasing amplitude of geminate rebinding is observed at increasing glycerol concentrations [148, 149]. At the same time several, well separated kinetic phases become evident in the rebinding kinetics [148].

The strong inhibition of protein fluctuations in the presence of high viscosity has remarkable consequences on the efficiency of escape of photodissociated ligands towards the solvent, generally resulting in a reduced escape probability. However, the extent of inhibition may be quite different from protein to protein. For some proteins, bimolecular rebinding is observed after laser photolysis even when protein gels are soaked in pure glycerol. This is the case of $\mathrm{AHb} 1$, for which the presence of an open tunnel connecting the distal cavity and the solvent $[138,150,151]$ allows exchange of ligands even under conditions where protein motions are enormously slowed down $[138,149,152]$.

$\mathrm{CO}$ rebinding to the related type 1 non symbiotic rice $\mathrm{Hb}$ (rHb1), a hexacoordinate $\mathrm{Hb}$, was recently investigated [153]. CO rebinding to $\mathrm{rHb} 1$ in solution shows a fast geminate phase of small amplitude and a bimolecular phase broadened by competitive distal His binding to and dissociation from the heme. Encapsulation in silica gel leads to appearance of multiple geminate phases, attributed to migration to internal cavities. When the FB10 mutant was studied, remarkable effects were observed on the rebinding kinetics, in which geminate phase and ligand migration through internal cavities were enhanced. As expected, mutation of the distal His resulted in suppression of hexacoordination. Unlike AHb1, when $\mathrm{rHb} 1$ gels are soaked in glycerol, the exchange between the protein matrix and the solvent becomes almost negligible, in agreement with the different shape in the cavities of the two proteins [150, $153,154]$.

When $\mathrm{CO}$ is photodissociated from $\mathrm{Ngb}$, geminate rebinding of small amplitude is observed on the nano- to microsecond time scale. This is followed by a biphasic kinetics where it is possible to identify a ligand concentration dependent bimolecular phase and a subsequent, much slower phase, which has been attributed to dissociation of the distal His from the heme [144, 155-157]. The relative weight of bimolecular rebinding and His dissociation kinetics is determined by ligand concentration and temperature [158]. Gel encapsulation of human $\mathrm{Ngb}$ revealed a surprising complexity in ligand migration through the cavities of the protein. Gel encapsulation by itself did not lead to dramatic changes in observed rates or amplitude of the different kinetic phases. However, when Ngb gels were soaked in glycerol, the geminate rebinding showed multiple phases, consistent with ligands being stored for hundreds of microseconds in secondary docking sites [159]. The enormous bulk viscosity and the sterical constraints imposed by the gel template completely inhibit formation of the bis-histidyl, hexacordinated species. The estimated energetic barriers demonstrate easy ligand migration through the cavities, except for the slowest reaction intermediate, possibly reflecting a conformational reshaping of the system of cavities. In the case of $\mathrm{Ngb}$, no bimolecular rebinding was observed for glycerol soaked gels, showing that exchange between the distal cavity and the solvent is highly inhibited, while efficient migration to remote cavities is maintained [159]. Transient docking of gaseous ligands in multiple binding sites, for times of up to several hundred microseconds, is consistent with NO dioxygenase activity, requiring the sequential reaction of two substrates with the heme [160]. Coupling of the ligand migration pathways with protein conformational changes may direct the specific sequence of events in the NO dioxygenase reaction [161].

The CO rebinding kinetics to Cygb (Fig. 4) shows a pattern similar to the one observed for Ngb [146, 162]. Photodissociated ligands can exit to the solvent following separate pathways, some of which exploit temporary docking sites [162] Hexacoordination by the distal His residue imposes large changes in energetic barriers that were suggested to modulate the flux of reactants to and products from the reaction site at the heme. Ligation appears to strongly affect CO rebinding kinetics to Cygb gels [162]. Cygb gels prepared by embedding unliganded Cygb (a bis-histidyl hexacoordinated species) allow easy formation of the $\mathrm{CO}$ adduct. $\mathrm{CO}$ rebinding kinetics to these gels is identical to the one observed for the protein in solution. Surprisingly, gels prepared by embedding COCygb lead to a rebinding kinetics that is almost completely lacking the long lived hexacoordinated intermediate.

\subsection{Protein Dynamics. Solvent Coupling of Protein Motions}

The origin of the increased protein stability in silica gels is complex. Direct (electrostatic or hydrogen bonding) interactions of the protein surface with the silica pore walls could be responsible for the observed restricted protein motions. On the other hand, the silica gel could influence the dynamics of encapsulated proteins by affecting the closely coupled dynamics of the aqueous solvent. Many studies have investigated water dynamics inside silica gel 
matrices [163-169]. Heterogeneous effects on solvent viscosity in silica gel pores have been reported [163,167, 170], mainly pointing to different viscosity increases (typically 1-2 orders of magnitude) depending on the specific encapsulation protocol, hydration level, pore size, etc. An estimate of the degree of coupling between protein motions and solvent can be obtained by estimating the effect of bulk viscosity on reaction rate constants. The Kramers theory for the effect of solvent viscosity on unimolecular rate processes $(k)$ in the condensed phase predicts an inverse proportionality between the measured rate constants and solvent friction, $\eta$ [171]. For more complex cases, where protein conformational changes are involved, an additional source of friction, $\sigma$, has been proposed, due to hindered intra-chain motion within the protein. This is regarded as an additive contribution to the friction from solvent molecules [172]. This model describes well the data in regime of moderately high viscosity [172], but fails to account for experimental observation of internal motion in rigid environments with very large external viscosity [173].

Using spectrally resolved infrared stimulated vibrational echo spectroscopy, Fayer and coworkers were able to demonstrate the correlation between the friction sensed by the gel encapsulated protein and the molecular size for $\mathrm{MbCO}$ and $\mathrm{HbCO}$ gels [174]. Gel encapsulated $\mathrm{MbCO}$ was found to exhibit dynamics comparable to those measured in a solution almost 20 times more viscous than bulk water. For the larger $\mathrm{HbCO}$ the gel was shown to introduce a 2-fold increase in viscosity.

Evidence for direct correlation between protein and solvent hindered dynamics has been obtained with optical absorption spectroscopy of the heme Soret band in encapsulated ferricytochrome c as a function of temperature [175]. In particular, the active site dynamics was shown to be sizably affected by freezing of a significant fraction of water co-encapsulated in silica gels at high hydration levels.

Further evidence of restricted protein dynamics in silica gels has been obtained with neutron scattering $[176,177]$. By measuring the protein hydrogen atoms mean-square displacements of encapsulated $\mathrm{Mb}$, a reduction of large-scale motions typically activated at temperature larger than $\sim 230 \mathrm{~K}$ was observed $[176,177]$, the effect depending markedly on sample hydration.

Ligand rebinding studies after flash-photolysis have also been widely used to investigate the effect induced by silica gel encapsulation on protein dynamics. Indeed, by analysing ligand rebinding kinetics measured in different encapsulating conditions in terms of specific microscopic kinetic models it is possible, on one hand, to correlate the calculated rates with structural or dynamical properties and, on the other hand, to obtain a more direct correlation between chemical-physical quantities and theoretical descriptions. For instance, this becomes evident when microscopic rates are confronted with models proposed to describe their viscosity dependence. The microscopic rate constants show an increasing degree of coupling when slower rates are considered. Faster processes like geminate recombination from the distal pocket show little if any coupling to bulk viscosity. The degree of coupling increases for slower processes (like migration to farther docking sites) and becomes fully consistent with Kramers law for much slower processes like bimolecular rebinding of an exogenous ligand, or His binding to and dissociation from the heme $[138,149]$. The concept of solvent slaving was applied by Friedman and co-workers when analyzing $\mathrm{CO}$ rebinding kinetics to $\mathrm{Hb}$ and $\mathrm{Mb}$ embedded in silica gels soaked in glycerol. The analysis of ligand rebinding kinetics to $\mathrm{R}$ and $\mathrm{T}$ state
$\mathrm{Hb}$ and to $\mathrm{Mb}$ suggests that progressively slower dynamics turn in after photodissociation [133].

\section{BIOTECHNOLOGICAL APPLICATIONS OF PROTEINS ENCAPSULATED IN SILICA GELS}

\subsection{Encapsulation of Enzymes}

Some biomolecules are endowed with the special property of catalyzing chemical reactions, i.e. they are able to increase by orders of magnitude the rate of a chemical transformation. The majority of biological catalysts are proteins, called enzymes. In addition, there are antibodies that have been selected to play the double role of recognizing a specific antigen and transforming it. A more recently discovered class of biological catalysts is represented by ribozymes and deoxyribozymes, short sequences of ribonucleic and deoxyribonucleic acids that are able to catalyze chemical reactions, although at very low rates. The catalytic power of enzymes and their substrate specificity arise from several distinct features, ranging from substrates orientation and proximity, substrate strain and distortion towards a transition state-like structure, acid-base catalysis, and covalent catalysis. Overall, enzymes act by altering the reaction mechanism and, in doing so, they decrease the activation barrier of the rate limiting step. Of paramount relevance for enzymes in achieving their function is the ability to adapt their conformation to the chemical structure of reaction intermediates, thus stabilizing them along the reaction coordinates. Therefore, enzyme function strongly depends on protein conformational changes. This feature can be exploited for increasing the catalytic power of an enzyme by selectively stabilizing alternative conformations. Entrapping enzymes in a polymeric matrix is a strategy that has been exploited to increase enzyme catalytic efficiency and/or enzyme stability. Indeed, enzymes were the first proteins to be immobilized in silica gels [2] in order to obtain bioreactors. Later, enzymes have been entrapped for the preparation of tailored biosensors and to unveil subtle enzyme structural and functional relationships. Reviews on immobilized enzymes have been reported $[8,9,13]$. Here, we present a few examples highlighting the power of encapsulating enzymes in silica gels. A few allosteric enzymes have been entrapped in silica gels with the aim to fix defined quaternary states, not as much to preserve and optimize activity, as to achieve a deeper insight in structure-function relationships, similarly to the approach pursued for hemoglobin and other heme proteins. The latter case studies are described in Section 3 above.

\subsubsection{Lipases}

Lipases catalyze the hydrolysis of esters, esterifications and transesterifications and several encapsulation matrices have been tested [178]. The surface area, the mean pore diameter and the pore volume of gels were determined and it was found that TEOS- and PEG-based gels exhibit a higher mean pore diameter, suggesting a role of PEG in preventing a volume reduction during gel formation. Lipases constitute a rare example of increase in activity when encapsulated in Ormosil gel, in comparison with silica gel: Reetz and coworkers [59] obtained lipase encapsulated in methyltrimethoxylsilane (MTMS) that exhibited about 1000-fold higher activity with respect to the free enzyme. This result might be explained by the stabilization of the open conformation of the enzyme by the apolar matrix, thus leading to a higher substrate accessibility.

Given the interest of lipase in different biotechnological applications ranging from laundry powder to enzyme processing plant components for the production of biodiesel, many papers have been published reporting strategies aimed at increasing lipase activity. A 
few representative investigations are reviewed below. Thermomyces lanuginosus lipase was characterized and encapsulated using differ ent silica precursors and dried using aerogel and xerogel techniques [179]. It was found that drying under supercritical $\mathrm{CO}_{2}$ provided higher enzymatic activities and larger pore sizes. Candida antarctica lipase B was sol-gel encapsulated using different protocols and used for the kinetic resolution of secondary alcohols [180]. Lipase from Pseudomonas cepacia was encapsulated in mesoporous silica gels with a moderately hydrophobic microenvironment. The immobilized protein exhibited an increased enzyme activity up to $281 \%$ and a higher thermal stability compared with the free lipase [181].

\subsubsection{Kinases and Phosphatases}

Kinases and phosphatases are distinct classes of enzymes catalyzing respectively the transfer of a phosphate group from ATP to a substrate and the hydrolysis of phosphoesters.

Creatine kinase, encapsulated in silica gel, exhibited an increase in long-term stability and thermal stability [182]. Moreover, when exposed to high temperatures, the enzyme exhibited increased activity. CD measurements, carried out before and after heating, suggested the occurrence of a temperature-dependent conformational change leading to the stabilization of a higher activity species.

Several silica gel precursors and additives, TMOS, TEOS and diglycerylsilane (DGS) either in the absence or presence of polyethilenoxide, were used for the preparation of biologically active Src protein tyrosine kinase gels [183]. It was found that DGS in the presence of a $10 \%$ molar ratio of $\mathrm{N}$-(3-triethoxylsilylpropyl) gluconate (GLTES) and ATP led to gels containing the enzyme as active as in solution. The role of GLTES is not well understood but it might prevent gel shrinkage, thus increasing pore size, whereas the role of ATP might be due to a substrate-induced conformational change, leading to the stabilization of an active enzyme. Src protein tyrosine kinase gels were assayed against polypeptide substrates with a molecular weight up to about $2000 \mathrm{Da}$, in the absence and presence of enzyme inhibitors. The calculated inhibition constants were very similar to those observed in solution, thus the encapsulated enzyme can be exploited for screening low molecular weight inhibitors.

Alkaline phosphatase, encapsulated in silica gels either in the absence or presence of the surfactants sodium bis(2-ethylexyl) sulfosuccinate (AOT) and cetyltrimethylammoniumbromide (CTAB) [184], exhibited a three-fold decrease in the turnover number with respect to the enzyme in solution, whereas the enzyme is still active at $\mathrm{pH} 2.4$ and $\mathrm{pH} \mathrm{13}$, where the enzyme in solution is inactive. AOT more than $\mathrm{CTAB}$ protects the enzyme against the extreme $\mathrm{pH}$ conditions. A similar protection was observed for acid phosphatase encapsulated at high $\mathrm{pH}$ values. The protecting behaviour of the gel matrix is likely due to the caging of the enzyme in a rigid matrix preventing or reducing the rate of denaturation, thus enabling the stabilization of an active conformation. These results are relevant for the exploitation of phosphatase in the development of biosensors or bioreactors operating under harsh conditions for soluble proteins.

\subsubsection{Pyridoxal 5'-phosphate Dependent Enzymes}

The pyridoxal 5'-phosphate dependent enzymes tryptophan synthase, tryptophan indole-lyase and tyrosine phenol-lyase have been entrapped in silica gels [185-187]. The encapsulated enzyme activity was assessed on micron size gels obtained by sonication in order to avoid diffusion limitation of the substrates. It was found that the catalytic activity was reduced and the steady-state distribution of catalytic intermediates, and their ketoenamine-enolimine tautomer equilibrium, were modified. These findings indicate that encapsulation altered enzyme conformational distribution, in particular the equilibrium between "open" and "closed" active site conformations.

\subsection{Proteins Encapsulated in Silica Gel as Biosensors}

The recent availability of recombinant proteins in large quantities and the accessibility of 'protein-friendly' immobilization techniques has suggested the design of biosensors based on immobilized biological macromolecules as sensing agents for the detection and quantification of analytes $[9,188]$. The range of analytes that can be detected through protein-based biosensors is huge, considering that Nature's repertoire offers a large number of proteins and polynucleotides that specifically bind or modify molecules, ranging from small ions, to aptamers [189], to large proteins and even microorganisms. In some cases, non-physiological biochemical properties [190] or engineered proteins with altered functional properties, have been exploited.

The principles underlying protein-based biosensors are usually similar to those of bioanalytical techniques in solution, largely used in clinical biochemistry thanks to the specificity and affinity of protein-ligand complexes, that allow for the discrimination of structurally and chemically similar analytes, as is often the case for biomolecules. The crucial difference between protein-based biosensors and conventional solution techniques is the immobilization of the sensing agent in a three-dimensional, stable and inert matrix. Immobilization not only physically confines proteins, allowing for their reuse, but also increases their stability at room temperature and resistance to thermal or $\mathrm{pH}$ denaturation. Moreover, encapsulation prevents the biosensing agent from interacting with proteins and other large molecules present in the sample, thus increasing further the durability of the sensor. Sometimes, encapsulation even results in favourable changes of the functional properties of proteins in comparison to solution.

As the immobilized protein interacts with the analyte, usually through a biospecific interaction, changes in its physicochemical properties are produced. These changes can then be monitored using a suitable detector coupled to the sensing probe. Several detection approaches can, in principle, be exploited: spectroscopic, electrochemical, calorimetric or magnetic [191]. Due to the simplicity of the techniques involved, absorption or emission in the UVvisible range are usually preferred, although electrochemical detection is also a potentially useful approach, particularly when the biosensor is based on a redox reaction [192].

Sensing proteins can simply bind the analyte, as in the case of antibodies, or catalyze reactions using the analytes as substrates, as in the case of enzymes. A simple ligand binding does not bring about easily detectable spectroscopic changes, unless chromophoric prostetic groups are present. When enzymes can be used, the formation of the product or the disappearance of the substrate can be monitored, rather than the direct binding of the protein to the ligand. Approaches of this kind are largely favoured, as catalysis hugely amplifies the signal and the measurement can greatly gain in sensitivity. In a few cases, the analyte of interest is an enzyme inhibitor, and its presence results in the slowing down of a reaction in the presence of the substrate [193].

Most of the immobilization matrices investigated so far are organic. However, since variants of the sol-gel method compatible with protein activity have been optimized (see Section 2), silica gels have also been used as encapsulation matrices. Silica gel is optically transparent in the UV-visible region of the spectrum, thus 
Table 1. List of biosensors based on encapsulated enzymes or microorganisms.

\begin{tabular}{|c|c|c|c|c|}
\hline Analyte & Sensing protein & Principle & Detection & Reference \\
\hline Acetazolamide & Carbonic anhydrase & $\begin{array}{l}\text { Inhibition of enzyme reaction by the } \\
\text { analyte }\end{array}$ & $\mathrm{pH}$ change detected with cresol red & [200] \\
\hline Acetylcholine & Acetylcholine esterase & Analyte as substrate & Fluorescence of a pH-sensitive dye & [201] \\
\hline ATP & Firefly Luciferase & Analyte as substrate & Bioluminescence & [202] \\
\hline ATP & $\begin{array}{l}\text { Glycerol kinase and glycerol 3- } \\
\text { phosphate oxidase }\end{array}$ & Analyte as substrate & Fluorescence & [203] \\
\hline Carbamate pesticides & Acetylcholine esterase & $\begin{array}{l}\text { Inhibition of enzyme reaction by the } \\
\text { analyte }\end{array}$ & $\begin{array}{l}\text { Potentiometric/ } \\
\text { conductimetric }\end{array}$ & [204] \\
\hline Catechol & Tyrosinase & Analyte as substrate & Amperometric & {$[205]$} \\
\hline Dopamine & Horseradish peroxidase & Analyte as substrate & Amperometric & [206] \\
\hline Glucose & Hexokinase & $\begin{array}{l}\text { Changes in the intrinsic spectroscopic } \\
\text { properties of the enzyme }\end{array}$ & Fluorescence & [207] \\
\hline Glucose & Glucose oxidase & $\begin{array}{l}\text { Glucose oxidation and generation of } \\
\text { hydrogen peroxide }\end{array}$ & Amperometric & [208] \\
\hline Heavy metals & Urease & $\begin{array}{l}\text { Inhibition of enzyme reaction by the } \\
\text { analyte }\end{array}$ & Fluorescence of a pH-sensitive dye & [201] \\
\hline Hydrogen peroxide & Horseradish peroxidase & Analyte as substrate & Colorimetric & [209] \\
\hline $\begin{array}{l}\text { Hydrogen peroxide ( } 3 \text { rd } \\
\text { generation biosensor) }\end{array}$ & Horseradish peroxidase & $\begin{array}{l}\text { Electron transfer between HRP and } \\
\text { the electrode surface }\end{array}$ & Amperometric & [210] \\
\hline $\begin{array}{l}\text { Inhibitors of tyrosine } \\
\text { kinases }\end{array}$ & Src protein tyrosine kinase & $\begin{array}{l}\text { Inhibition of enzyme reaction by the } \\
\text { analyte }\end{array}$ & Fluorescence & [183] \\
\hline Lactic acid & Lactate dehydrogenase & Analyte as substrate & Amperometric & [211] \\
\hline Microcystin & Protein phosphatase $2 \mathrm{~A}$ & $\begin{array}{l}\text { Inhibition of enzyme reaction by the } \\
\text { analyte }\end{array}$ & Colorimetric & [212] \\
\hline $\begin{array}{l}\text { Organophosphorous } \\
\text { pesticides }\end{array}$ & Acetylcholinesterase & $\begin{array}{l}\text { Competition of analytes with enzyme } \\
\text { reaction }\end{array}$ & Amperometric & [213] \\
\hline Pesticides & Acetylcholinesterase & Analyte as enzyme inhibitor & Fluorimetric & [214] \\
\hline Pollutants & Microalgi & Esterase activity on fluoresceine & Fluorescence & [215] \\
\hline Superoxide anion & Superoxide dismutase & Analyte as substrate & Amperometric & [216] \\
\hline Urea & Urease & Analyte as substrate & Fluorescence of a pH-sensitive dye & [201] \\
\hline Various & DNA aptamers & & Fluorescence & [217] \\
\hline Xanthine & $\begin{array}{l}\text { Xanthine oxidasel superoxide } \\
\text { dismutaselperoxidase }\end{array}$ & Analyte as substrate & Fluorimetric & [194] \\
\hline
\end{tabular}

allowing for the application of absorption or emission detection techniques. Moreover, silica gel preparations can be easily miniaturized and layered on different surfaces. Several additives can be added to the sol-gel in different phases of the preparation, resulting in "tailored materials" suitable for a number of proteins and detection systems [50]. Table 1 summarizes some applications of silica gel-encapsulated proteins reported in the literature [183, 194, 200217]. Notable examples include cases in which more proteins are co-encapsulated to immobilize short metabolic pathways [194]. Biosensors based on modified silica gels have been recently reviewed [50].
Due to the biocompatibility of silica gel $[195,196]$ this material has been tested as immobilization matrix for in vivo biosensors [197], devices that can be permanently or temporarily implanted in vivo to continuously monitor the concentration of analytes. The use of these devices offers several advantages over conventional ex vivo systems, particularly as they would reduce the need for blood sampling and the risk of pre-analytical alteration of the sample. As for other biosensors, biosensors to be used in vivo require the coupling of the enzyme that interacts with the analyte with a detector element. 
Whereas the early designs of biosensors based on silica gelencapsulated biomolecules were in the form of monoliths and powders, now more configurations are available, including thin films, fibres and microarrays [50], all taking advantage of the rheological properties of silica gel and the versatility of the sol-gel method. Thin films were introduced to reduce the diffusion times of the analytes, and hence, reduce the response time of the biosensor. They can also be miniaturized and layered on conventional detection systems, such as optical fibres and electrodes. Dip casting, spray coating and spin coating techniques have all been employed [198]. The printing of silica gels doped with macromolecules is also emerging as a useful approach, as it requires small volumes, is highly reproducible and amenable to be incorporated into multianalyte biosensors and multiple layers [199]. To this aim, inkjet technology has been adapted to produce printed biosensors on surfaces. Overall, the combination of technologies that require small amounts of protein doped-silica gel, and the capability of depositing them on different surfaces points towards the production of microarrays for multianalyte, high throughput systems [50].

\section{CONFLICT OF INTEREST}

The authors confirm that this article content has no conflict of interest.

\section{ACKNOWLEDGEMENTS}

Declared none.

\section{LIST OF ABBREVIATIONS}

$\begin{array}{lll}\mathrm{AOT} & = & \text { bis(2-ethylexyl) sulfosuccinate } \\ \mathrm{ATCa} e & = & \text { aspartate transcarbamoylase } \\ \mathrm{CTAB} & = & \text { cetyltrimethylammoniumbromide } \\ \mathrm{Cygb} & = & \text { cytoglobin } \\ \mathrm{DGS} & = & \text { diglycerylsilane } \\ \mathrm{GDH} & = & \text { glutamate dehydrogenase } \\ \mathrm{GLTES} & = & \mathrm{N}-(3 \text {-triethoxylsilylpropyl)gluconate } \\ \mathrm{Hb} & = & \text { hemoglobin } \\ \mathrm{Mb} & = & \text { myoglobin } \\ \mathrm{MTMS} & = & \text { methyltrimethoxylsilane } \\ \mathrm{Ngb} & = & \text { neuroglobin } \\ \mathrm{PEG} & = & \text { polyethylene glycol } \\ \mathrm{PVA} & = & \text { polyvinyl alcohol } \\ \mathrm{TEOS} & = & \text { tetraethyl orthosilicate } \\ \mathrm{TMOS} & = & \text { tetramethyl orthosylicate }\end{array}$

\section{REFERENCES}

[1] Olson, A.C.; Cooney, C.L. Immobilized enzymes in food and microbial processes; Plenum Pub. Corp.: New York, 1973.

[2] Avnir, D.; Braun, S.; Lev, O.; Ottolenghi, M. Enzymes and other proteins entrapped in sol-gel materials. Chem. Mater., 1994, 6(10), 1605-1614.

[3] Braun, S.; Rappoport, S.; Zusman, R.; Avnir, D.; Ottolenghi, M. Biochemically active sol-gel glasses - the trapping of enzymes. Mater. Lett., 1990, $10(1-2), 1-5$.

[4] Ellerby, L.; Nishida, C.R.; Nishida, F.; Yamanaka, S.A.; Dunn, B.; Valentine, J.S.; Zink, J.I. Encapsulation of proteins in transparent porous silicate glasses prepared by the sol-gel method. Science, 1992, 255, 11131115 .

[5] Calabretta, P.J.; Chancellor, M.C.; Torres, C.; Abel, G.R.; Niehaus, C.; Birtwhistle, N.J.; Khouderchah, N.M.; Zemede, G.H.; Eggers, D.K. Silica as a matrix for encapsulating proteins: Surface effects on protein structure assessed by circular dichroism spectroscopy. J. Funct. Biomater., 2012, 3(3), 514-527.
Menaa, B.; Herrero, M.; Rives, V.; Lavrenko, M.; Eggers, D.K. Favourable influence of hydrophobic surfaces on protein structure in porous organicallymodified silica glasses. Biomaterials, 2008, 29(18), 2710-2718.

[7] Menaa, B.; Miyagawa, Y.; Takahashi, M.; Herrero, M.; Rives, V.; Menaa, F. Eggers, D.K. Bioencapsulation of apomyoglobin in nanoporous organosilica sol-gel glasses: Influence of the siloxane network on the conformation and stability of a model protein. Biopolymers, 2009, 91(11), 895-906.

[8] Bettati, S.; Pioselli, B.; Campanini, B.; Viappiani, C.; Mozzarelli, A. Proteindoped nanoporous silica gels. In: Encyclopedia of Nanoscience and Nanotechnology; Nalwa, H.S., Ed.; American Scientific Publishers, 2004; Vol. 9, pp. 81-103.

[9] Bruno, S.; Ronda, L.; Abbruzzetti, S.; Viappiani, C.; Bettati, S.; Kumar Maji, S.; Mozzarelli, A. Protein encapsulation, conformations and nanobiotools. In: Encyclopedia of Nanoscience and Nanotechnology; Nalwa, H.S., Ed.; American Scientific Publishers, 2011; Vol. 21, pp. 481-517.

[10] Gill, I. Bio-doped nanocomposite polymers: Sol-gel bioencapsulates. Chem Mater., 2001, 13(10), 3404-3421.

[11] Gill, I.; Ballesteros, A. Encapsulation of biologicals within silicate, siloxane, and hybrid sol-gel polymers: An efficient and generic approach. J. Am. Chem. Soc., 1998, 120(34), 8587-8598.

[12] Gill, I.; Ballesteros, A. Bioencapsulation within synthetic polymers (part 1): Sol-gel encapsulated biologicals. Trends Biotechnol., 2000, 18(7), 282-296.

[13] Jin, W.; Brennan, J.D. Properties and applications of proteins encapsulated within sol-gel derived materials. Anal. Chim. Acta, 2002, 461(1), 1-36.

[14] Mozzarelli, A.; Bettati, S. Functional properties of immobilized proteins. In: Advanced Functional Molecules and Polymers; Nalwa, H.S., Ed.; Overseas Publishers Association: Tokyo, 2001; Vol. 4, pp. 55-97.

[15] Avnir, D.; Coradin, T.; Lev, O.; Livage, J. Recent bio-applications of sol-gel materials. J. Mater. Chem., 2006, $16(11), 1013-1030$

[16] Betancor, L.; Luckarift, H.R. Bioinspired enzyme encapsulation for biocatalysis. Trends Biotechnol., 2008, 26(10), 566-572.

[17] Brennan, J.D. Biofriendly sol-gel processing for the entrapment of soluble and membrane-bound proteins: Toward novel solid-phase assays for highthroughput screening. Acc. Chem. Res., 2007, 40(9), 827-835.

[18] Livage, J.; Coradin, T.; Roux, C. Encapsulation of biomolecules in silica gels. J. Phys. Condens. Matt., 2001, 13(33), R673-R691.

[19] Wang, X.L.; Ben Ahmed, N.; Alvarez, G.S.; Tuttolomondo, M.V.; Helary, C.; Desimone, M.F.; Coradin, T. Sol-gel encapsulation of biomolecules and cells for medicinal applications. Curr. Top. Med. Chem., 2015, 15(3), 223244

[20] Chiriac, A.P.; Neamtu, I.; Nita, L.E.; Nistor, M.T. Sol gel method performed for biomedical products implementation. Mini Rev. Med. Chem., 2010, 10(11), 990-1013.

[21] Gupta, R.; Kumar, A. Bioactive materials for biomedical applications using sol-gel technology. Biomed. Mater., 2008, 3(3), 034005.

[22] Coradin, T.; Boissiere, M.; Livage, J. Sol-gel chemistry in medicinal science. Curr. Med. Chem., 2006, 13(1), 99-108

[23] Brinker, C.J.; Scherer, G.W. Sol-gel science: The Physics and Chemistry of Sol-gel Processing; Academic Press: Boston, 1990.

[24] Iucci, G.; Infante, G.; Rossi, L.; Polzonetti, G.; Rosato, N.; Avigliano, L.; Savini, I.; Catani, M.V.; Palacios, A.C. Albumin containing sol-gel glasses: Chemical and biological study. J. Mater. Sci. Mater. Med., 2004, 15(5), 601606 .

[25] Sykora, M.; Maxwell, K.A.; Meyer, T.J. Sio(2) sol-gel composite films containing redox-active, polypyridyl-ruthenium polymers. Inorg. Chem. 1999, 38(16), 3596-3597.

[26] Pierre, A.C. The sol-gel encapsulation of enzymes. Biocatal. Biotransform. 2004, 22(3), 145-170.

[27] Hench, L.L.; West, J.K. The sol-gel process. Chem. Rev., 1990, 90(1), 33-72.

[28] Livage, J.; Lemerle, J. Transition metal oxide gels and colloids. Ann. Rev. Mater. Sci., 1982, 12, 103-122.

[29] Meixner, D.L.; Dyer, P.N. Influence of sol-gel synthesis parameters on the microstructure of particulate silica xerogels. J. Sol-Gel Sci. Technol., 1999, 14(3), 223-232.

[30] Brinker, C.J.; Keefer, K.D.; Schaefer, D.W.; Assink, R.A.; Kay, B.D. Ashley, C.S. Sol-gel transition in simple silicates II. J. Non-Cryst. Solids, 1984, 63(1-2), 45-59.

[31] Pohl, E.R.; Osterholtz, F.D. Kinetics and mechanism of aqueous hydrolysis and condensation of alkyltrialkoxysilanes. In: Molecular characterization of Composite Interfaces. Polymer Science and Technology; Springer: Berlin Heidelberg, 1985; pp.157-170

[32] Iler, R.K. The Chemistry of Silica: Solubility, Polymerization, Colloid and Surface Properties, and Biochemistry; Wiley-Interscience: New York, 1979.

[33] Voronkov, M.G.; Mileshkevich, V.P.; Yuzhelevskii, Y.A. The Siloxane Bond; Plenum Press: Consultant Bureau - New York and London, 1978.

[34] Dunn, B.; Zink, J.I. Probes of pore environment and molecule-matrix interactions in sol-gel materials. Chem. Mater., 1997, 9(11), 2280-2291.

[35] Buckley, A.M.; Greenblatt, M. The sol-gel preparation of silica gels. J. Chem. Edu., 1994, 71(7), 599-602.

[36] Flora, K.; Brennan, J.D. Fluorometric detection of $\mathrm{Ca}^{2+}$ based on an induced change in the conformation of sol-gel entrapped parvalbumin. Anal. Chem. 1998, 70(21), 4505-4513.

[37] Zheng, L.; Brennan, J.D. Measurement of intrinsic fluorescence to probe the conformational flexibility and thermodynamic stability of a single tryptophan 
protein entrapped in a sol-gel derived glass matrix. Analyst, 1998, 123(8), $1735-1744$.

[38] Kauffmann, C.; Mandelbaum, R.T. Entrapment of atrazine chlorohydrolase in sol-gel glass matrix. J. Biotechnol., 1998, 62(3), 169-176.

[39] Reetz, M.T.; Zonta, A.; Simpelkamp, J. Efficient immobilization of lipases by entrapment in hydrophobic sol-gel materials. Biotechnol. Bioeng., 1996, 49(5), 527-534.

[40] Altstein, M.; Segev, G.; Aharonson, N.; Ben-Aziz, O.; Turniansky, A.; Avnir, D. Sol-gel-entrapped cholinesterases: A microtiter plate method for monitoring anti-cholinesterase compounds. J. Agric. Food. Chem., 1998, 46(8), 3318-3324

[41] Wang, B.Q.; Li, B.; Deng, Q.; Dong, S.J. Amperometric glucose biosensor based on sol-gel organic-inorganic hybrid material. Anal. Chem., 1998, 70(15), 3170-3174

[42] Wang, B.Q.; Zhang, J.Z.; Cheng, G.J.; Dong, S.J. Amperometric biosensor for inert organic solvents based on a sol-gel hybrid material. Chem. Commun., 2000, (21), 2123-2124.

[43] Zhang, J.; Li, B.; Wang, Z.; Cheng, G.; Dong, S. Functionalized inorganicorganic composite material derivated by sol-gel for construction of mediated amperometric hydrogen peroxide biosensor. Anal. Chim. Acta, 1999, 388(12), 71-78

[44] Chen, Q.; Kenausis, G.L.; Heller, A. Stability of oxidases immobilized in silica gels. J. Am. Chem. Soc., 1998, 120(19), 4582-4585.

[45] Heller, J.; Heller, A. Loss of activity or gain in stability of oxidases upon their immobilization in hydrated silica: Significance of the electrostatic interactions of surface arginine residues at the entrances of the reaction channels. J. Am. Chem. Soc., 1998, 120(19), 4586-4590.

[46] Eggers, D.K.; Valentine, J.S. Crowding and hydration effects on protein conformation: A study with sol-gel encapsulated proteins. J. Mol. Biol., 2001, 314(4), 911-922.

[47] Brennan, J.D.; Benjamin, D.; DiBattista, E.; Gulcev, M.D. Using sugar and amino acid additives to stabilize enzymes within sol-gel derived silica. Chem. Mater., 2003, 15(3), 737-745.

[48] Wang, G.H.; Zhang, L.M. A biofriendly sol-gel route to new hybrid gels for enzyme encapsulation. $J$. Sol-Gel Sci. Technol., 2014, 72(1), 85-91.

[49] Gamero-Quijano, A.; Huerta, F.; Morallon, E.; Montilla, F. Modulation of the silica sol-gel composition for the promotion of direct electron transfer to encapsulated cytochrome C. Langmuir, 2014, 30(34), 10531-10538.

[50] Monton, M.R.N.; Forsberg, E.M.; Brennan, J.D. Tailoring sol-gel-derived silica materials for optical biosensing. Chem. Mater., 2012, 24(5), 796-811. Zeno, W.F.; Hilt, S.; Aravagiri, K.K.; Risbud, S.H.; Voss, J.C.; Parikh, A.N.; Longo, M.L. Analysis of lipid phase behavior and protein conformational changes in nanolipoprotein particles upon entrapment in sol-gel-derived silica. Langmuir, 2014, 30(32), 9780-9788

[52] Sotiropoulou, S.; Chaniotakis, N.A. Tuning the sol-gel microenvironment for acetylcholinesterase encapsulation. Biomaterials, 2005, 26(33), 6771-6779.

[53] Zheng, L.L.; Flora, K.; Brennan, J.D. Improving the performance of a solgel-entrapped metal-binding protein by maximizing protein thermal stability before entrapment Chem Mater, 1998, 10(12), 3974-3983.

[54] Bruno, S.; Ronda, L.; Bettati, S.; Mozzarelli, A. Trapping hemoglobin in rigid matrices: Fine tuning of oxygen binding properties by modulation of encapsulation protocols. Artif. Cells. Blood Substit. Immobil. Biotechnol., 2007, 35(1), 69-79.

[55] Bottini, M.; Di Venere, A.; Tautz, L.; Desideri, A.; Lugli, P.; Avigliano, L.; Rosato, N. Structural stability of azurin encapsulated in sol-gel glasses: A fluorometric study. J. Sol-Gel Sci. Technol., 2004, 30(3), 205-214.

[56] Fuentes, L.; Oyola, J.; Fernandez, M.; Quinones, E. Conformational changes in azurin from pseudomona aeruginosa induced through chemical and physical protocols. Biophys. J., 2004, 87(3), 1873-1880.

[57] Bettati, S.; Mozzarelli, A. T state hemoglobin binds oxygen noncooperatively with allosteric effects of protons, inositol hexaphosphate and chloride. J. Biol. Chem., 1997, 272, 32050-32055.

[58] Viappiani, C.; Bettati, S.; Bruno, S.; Ronda, L.; Abbruzzetti, S.; Mozzarelli, A.; Eaton, A.W. New insights into allosteric mechanisms from trapping unstable protein conformations in silica gels. Proc. Natl. Acad. Sci. U.S.A., 2004, 101, 14414-14419.

[59] Reetz, M.T.; Zonta, A.; Simpelkamp, J. Efficient heterogeneous biocatalysts by entrapment of lipases in hydrophobic sol-gel materials. Angew. Chem.-Int. Edit. Engl., 1995, 34(3), 301-303.

[60] Frauenfelder, H.; McMahon, B.H.; Austin, R.H.; Chu, K.; Groves, J.T. The role of structure, energy landscape, dynamics, and allostery in the enzymatic function of myoglobin. Proc. Natl. Acad. Sci. U.S.A., 2001, 98, 2370-2374.

[61] Frauenfelder, H.; Park, F.; Young, R.D. Conformational substates in proteins. Annu. Rev. Biophys. Biophys. Chem., 1988, 17, 451-479.

[62] Thirumalai, D.; Klimov, D.K.; Lorimer, G.H. Caging helps proteins fold. Proc. Natl. Acad. Sci. U.S.A., 2003, 100(20), 11195-11197.

[63] Cheung, M.S.; Klimov, D.; Thirumalai, D. Molecular crowding enhances native state stability and refolding rates of globular proteins. Proc. Natl. Acad. Sci. U.S.A., 2005, 102(13), 4753-4758.

[64] Cheung, M.S.; Thirumalai, D. Nanopore-protein interactions dramatically alter stability and yield of the native state in restricted spaces. J. Mol. Biol., 2006, 357(2), 632-643.
[65] Klimov, D.K.; Newfield, D.; Thirumalai, D. Simulations of $\beta$-hairpin folding confined to spherical pores using distributed computing. Proc. Natl. Acad. Sci. U.S.A., 2002, 99, 8019-8024.

[66] Minton, A.P. Influence of macromolecular crowding upon the stability and state of association of proteins: Predictions and observations. J. Pharm. Sci., 2005, 94(8), 1668-1675.

[67] Zhou, H.X. Polymer models of protein stability, folding, and interactions. Biochem., 2004, 43(8), 2141-2154

[68] Zhou, H.X. Protein folding and binding in confined spaces and in crowded solutions. J. Mol. Recognit., 2004, 17(5), 368-375.

[69] Zhou, H.X. Loops, linkages, rings, catenanes, cages, and crowders: Entropybased strategies for stabilizing proteins. Acc. Chem. Res., 2004, 37(2), 123 130

[70] Zhou, H.X.; Dill, K.A. Stabilization of proteins in confined spaces. Biochem., 2001, 40(38), 11289-11293.

[71] Kapoor, S.; Mandal, S.S.; Bhattacharyya, A.J. Structure and function of hemoglobin confined inside silica nanotubes. J. Phys. Chem. B, 2009, 113(43), 14189-14195.

[72] Vaitheeswaran, S.; Thirumalai, D. Entropy and enthalpy of interaction between amino acid side chains in nanopores. J. Chem. Phys., 2014, 141(22),

[73] Ravindra, R.; Shuang, Z.; Gies, H.; Winter, R. Protein encapsulation in mesoporous silicate: The effects of confinement on protein stability, hydration, and volumetric properties. J. Am. Chem. Soc., 2004, 126(39), 12224-12225.

[74] Ping, G.; Yuan, J.M.; Sun, Z.F.; Wei, Y. Studies of effects of macromolecular crowding and confinement on protein folding and protein stability. J. Mol. Recognit., 2004, 17(5), 433-440.

[75] Yamanaka, S.A.; Nguyen, N.P.; Dunn, B.; Valentine, J.S.; Zink, J.I. Enzymatic activity of oxalate oxidase and kinetic measurements by optica methods in transparent sol-gel monoliths. J. Sol-Gel Sci. Technol., 1996, 7(12), 117-121.

[76] Pastor, I.; Ferrer, M.L.; Lillo, M.P.; Gomez, J.; Mateo, C.R. Structure and dynamics of lysozyme encapsulated in a silica sol-gel matrix. J. Phys. Chem $B$, 2007, 111(39), 11603-11610.

[77] Pastor, I.; Prieto, M.; Mateo, C.R. Effect of sol-gel confinement on the structural dynamics of the enzyme bovine $\mathrm{Cu}, \mathrm{Zn}$ superoxide dismutase. $J$. Phys. Chem. B, 2008, 112(47), 15021-15028.

[78] Gupta, R.; Chaudhury, N.K. Entrapment of biomolecules in sol-gel matrix for applications in biosensors: Problems and future prospects. Biosens. Bioelectron., 2007, 22(11), 2387-2399.

[79] Menaa, B.; Menaa, F.; Aiolfi-Guimaraes, C.; Sharts, O. Silica-based nanoporous sol-gel glasses: From bioencapsulation to protein folding studies. Int. J. Nanotechnol., 2010, 7(1), 1-45.

[80] Ronda, L.; Abbruzzetti, S.; Bruno, S.; Bettati, S.; Mozzarelli, A.; Viappiani, C. Ligand-induced tertiary relaxations during the T-to-R quaternary transition in hemoglobin. J. Phys. Chem. B, 2008, 112, 12790-12794.

[81] Ronda, L.; Bruno, S.; Viappiani, C.; Abbruzzetti, S.; Mozzarelli, A.; Lowe, K.C.; Bettati, S. Circular dichroism spectroscopy of tertiary and quaternary conformations of human hemoglobin entrapped in wet silica gels. Protein Sci., 2006, 15, 1961-1967.

[82] Shibayama, N.; Saigo, S. Fixation of the quaternary structures of human adult haemoglobin by encapsulation in transparent porous silica gels. J. Mol. Biol., 1995, 251, 203-209.

[83] Shibayama, N.; Saigo, S. Kinetics of the allosteric transition in hemoglobin within silicate sol-gels. J. Am. Chem. Soc., 1999, 121, 444-445.

[84] Shibayama, N.; Saigo, S. Oxygen equilibrium properties of myoglobin locked in the liganded and unliganded conformations. J. Am. Chem. Soc., 2003, $125,3780-3783$.

[85] Viappiani, C.; Abbruzzetti, S.; Ronda, L.; Bettati, S.; Henry, E.R.; Mozzarelli, A.; Eaton, W.A. Experimental basis for a new allosteric mode for multisubunit proteins. Proc. Natl. Acad. Sci. U.S.A., 2014, 111, 1275812763.

[86] Juszczak, L.J.; Friedman, J.M. UV resonance raman spectra of ligand binding intermediates of sol-gel encapsulated hemoglobin. J. Biol. Chem., 1999, 274, 30357-30360.

[87] Khan, I.; Shannon, C.F.; Dantsker, D.; Friedman, A.J.; Perez-Gonzales-deApodaca, J.; Friedman, J.M. Sol-gel trapping of functional intermediates of hemoglobin: Geminate and bimolecular recombination studies. Biochem., 2000, 39, 16099-16109.

[88] Levantino, M.; Cupane, A.; Zimanyi, L. Quaternary structure dependence of kinetic hole burning and conformational substates interconversion in hemoglobin. Biochem., 2003, 42, 4499-4505.

[89] Samuni, U.; Dantsker, D.; Juszczak, L.J.; Bettati, S.; Ronda, L.; Mozzarelli, A.; Friedman, J.M. Spectroscopic and functional characterization of T state hemoglobin conformations encapsulated in silica gels. Biochem., 2004, 43 , 13674-13682.

[90] Samuni, U.; Dantsker, D.; Khan, I.; Friedman, A.J.; Peterson, E.; Friedman, J.M. Spectroscopically and kinetically distinct conformational populations of sol-gel-encapsulated carbonmonoxy myoglobin. J. Biol. Chem., 2002, 277, 25783-25790.

[91] Schiro, G.; Cammarata, M.; Levantino, M.; Cupane, A. Spectroscopic markers of the $\mathrm{T}<->\mathrm{R}$ quaternary transition in human hemoglobin. Biophys. Chem., 2005, 114(1), 27-33 
[92] Schirò, G.; Cupane, A. Quaternary relaxations in sol-gel encapsulated hemoglobin studied via NIR and UV spectroscopy. Biochem., 2007, 46, 11568-11576.

[93] Droghetti, E.; Smulevich, G. Effect of sol-gel encapsulation on the unfolding of ferric horse heart cytochrome C. J. Biol. Inorg. Chem., 2005, 10(6), 696703.

[94] Fiandaca, G.; Vitrano, E.; Cupane, A. Ferricytochrome C encapsulated in silica nanoparticles: Structural stability and functional properties. Biopolymers, 2004, 74(1-2), 55-59.

[95] Shibayama, N. Slow motion analysis of protein folding intermediates within wet silica gels. Biochem., 2008, 47(21), 5784-5794.

[96] Okabe, T.; Tsukamoto, S.; Fujiwara, K.; Shibayama, N.; Ikeguchi, M. Delineation of solution burst-phase protein folding events by encapsulating the proteins in silica gels. Biochem., 2014, 53(23), 3858-3866.

[97] Bottini, M.; De Venere, A.; Lugli, P.; Rosato, N. Conformation and stability of myoglobin in dilute and crowded organically modified media. J. NonCryst. Solids, 2004, 343(1-3), 101-108.

[98] Roche, C.J.; Guo, F.; Friedman, J.M. Molecular level probing of preferential hydration and its modulation by osmolytes through the use of pyranine complexed to hemoglobin. J. Biol. Chem., 2006, 281, 38757-38768.

[99] Peterson, E.S.; Leonard, E.F; Foulke, J.A.; Oliff, M.C.; Salisbury, R.D.; Kim, D.Y. Folding myoglobin within a sol-gel glass: Protein folding constrained to a small volume. Biophys. J., 2008, 95(1), 322-332.

[100] Bruno, S.; Bonaccio, M.; Bettati, S.; Rivetti, C.; Viappiani, C.; Abbruzzetti, S.; Mozzarelli, A. High and low oxygen affinity conformations of T state hemoglobin. Protein Sci., 2001, 10(11), 2401-2407.

[101] Shibayama, N.; Saigo, S. Direct observation of two distinct affinity conformations in the $\mathrm{T}$ state human deoxyhemoglobin. FEBS Lett., 2001, 429, 50-53

[102] Minton, A.P. The influence of macromolecular crowding and macromolecular confinement on biochemical reactions in physiological media. J. Biol. Chem., 2001, 276, 10577-10580.

[103] Minton, A.P. How can biochemical reactions within cells differ from those in test tubes? J. Cell Sci., 2006, $119(14), 2863-2869$.

[104] Eggers, D.K.; Valentine, J.S. Molecular confinement influences protein structure and enhances thermal protein stability. Protein Sci., 2001, 10, 250261.

[105] Sottini, S.; Viappiani, C.; Ronda, L.; Bettati, S.; Mozzarelli, A. Co rebinding kinetics to myoglobin- and r-state-hemoglobin- doped silica gels in the presence of glycerol. J. Phys. Chem. B, 2004, 108(24), 8475-8484.

[106] Campanini, B.; Bologna, S.; Cannone, F.; Chirico, G.; Mozzarelli, A.; Bettati, S. Unfolding of green fluorescent protein mut2 in wet nanoporous silica gels. Protein Sci., 2005, 14, 1125-1133.

[107] Campanini, B.; Pioselli, B.; Raboni, S.; Felici, P.; Giordano, I.; D'Alfonso, L.; Collini, M.; Chirico, G.; Bettati, S. Role of histidine 148 in stability and dynamics of a highly fluorescent GFP variant. BBA Proteins Proteom., 2013, 1834(4), 770-779.

[108] Cormack, B.P.; Valdivia, R.H.; Falkow, S. Facs-optimized mutants of the green fluorescent protein (GFP). Gene, 1996, 173(1), 33-38.

[109] Chirico, G.; Cannone, F.; Beretta, S.; Diaspro, A.; Campanini, B.; Bettati, S.; Ruotolo, R.; Mozzarelli, A. Dynamics of green fluorescent protein mutant2 in solution, on spin-coated glasses, and encapsulated in wet silica gels. Protein Sci., 2002, 11, 1152-1161

[110] Campanini, B.; Bologna, S. Protein denaturation in wet nanoporous silica gels: Effect of caging and crowding on the dynamics of GFPmut2. Nuovo Cimento C, 2004, 27(5), 517-528

[111] Baldini, G.; Cannone, F.; Chirico, G.; Collini, M.; Campanini, B.; Bettati, S.; Mozzarelli, A. Evidence of discrete substates and unfolding pathways in green fluorescent protein. Biophys. J., 2007, 92, 1724-1731.

[112] Myers, J.K.; Oas, T.G. Mechansim of fast protein folding. Annu. Rev. Biochem., 2002, 71, 783-815.

[113] Cannone, F.; Caccia, M.; Bologna, S.; Diaspro, A.; Chirico, G. Single molecule spectroscopic characterization of GFP-mut2 mutant for two-photon microscopy applications. Microsc. Res. Tech., 2004, 65(4-5), 186-193.

[114] Cannone, F.; Bologna, S.; Campanini, B.; Diaspro, A.; Bettati, S.; Mozzarelli, A.; Chirico, G. Tracking unfolding and refolding of single GFPmut2 molecules. Biophys. J., 2005, 89(3), 2033-2045.

[115] Luo, G.M.; Zhang, Q.; Del Castillo, A.R.; Urban, V.; O'Neill, H. Characterization of sol-gel-encapsulated proteins using small-angle neutron scattering. ACS Appl. Mater. Interfaces, 2009, I(10), 2262-2268.

[116] Kantrowitz, E.R. Allostery and cooperativity in escherichia coli aspartate transcarbamoylase. Arch. Biochem. Biophys., 2012, 519(2), 81-90.

[117] Lipscomb, W.N.; Kantrowitz, E.R. Structure and mechanisms of escherichia coli aspartate transcarbamoylase. Acc. Chem. Res., 2012, 45(3), 444-453.

[118] West, J.M.; Kantrowitz, E.R. Trapping specific quaternary states of the allosteric enzyme aspartate transcarbamoylase in silica matrix sol-gels. $J$. Am. Chem. Soc., 2003, 125, 9924-9925.

[119] McIninch, J.K.; Kantrowitz, E.R. Use of silicate sol-gels to trap the $r$ and $t$ quaternary conformational states of pig kidney fructose-1,6-bisphosphatase. BBA Protein Struct. M., 2001, 1547, 320-328.

[120] Husing, N.; Reisler, E.; Zink, J.I. Allosteric regulation of enzymatic reactions in a transparent inorganic sol-gel material. J. Sol-Gel Sci. Technol., 1999, 15(1), 57-61.

[121] Zonszein, S.; Alvarez-Anorve, L.I.; Vazquez-Nunez, R.J.; Calcagno, M.L. The tertiary origin of the allosteric activation of E. coli glucosamine-6- phosphate deaminase studied by sol-gel nanoencapsulation of its t conformer. PLoS ONE, 2014, 9(5), e96536.

[122] Henry, E.R.; Bettati, S.; Hofrichter, J.; Eaton, W.A. A tertiary two-state allosteric model for hemoglobin. Biophys. Chem., 2002, 98, 149-164.

[123] Changeux, J.P. 50 years of allosteric interactions: The twists and turns of the models. Nat. Rev. Mol. Cell. Biol., 2013, 14(12), 819-829.

[124] Cammarata, M.; Levantino, M. Wulff, M. Cupane, A. Unveiling the timescale of the $\mathrm{r}-\mathrm{t}$ transition in human hemoglobin. J. Mol. Biol., 2010, 400, 951-962.

[125] Levantino, M.; Spilotros, A.; Cammarata, M.; Schirò, G.; Ardiccioni, C Vallone, B.; Brunori, M.; Cupane, A.; The Monod-Wyman-Changeux allosteric model accounts for the quaternary transition dynamics in wild type and a recombinant mutant human hemoglobin. Proc. Natl. Acad. Sci. U.S.A., 2012, 109(37), 14894-14899.

[126] Das, T.K.; Khan, I.; Rousseau, D.; Friedman, J.M. Temperature dependent quaternary state relaxation. Biospectroscopy, 1999, 5, S64-S70

[127] Abbruzzetti, S.; Viappiani, C.; Bruno, S.; Bettati, S.; Bonaccio, M. Mozzarelli, A. Functional characterization of heme proteins encapsulated in wet nanoporous silica gels. J. Nanosci. Nanotechnol., 2001, 1(4), 407-415.

[128] Jones, E.M.; Balakrishnan, G.; Spiro, T.G. Heme reactivity is uncoupled from quaternary structure in gel-encapsulated hemoglobin: A resonance raman spectroscopic study. J. Am. Chem. Soc., 2012, 134, 3461-3471.

[129] Dantsker, D.; Samuni, U.; Friedman, A.J.; Yang, M.; Ray, A.; Friedman, J.M. Geminate rebinding in trehalose-glass embedded myoglobins reveals residue-specific control of intramolecular trajectories. J. Mol. Biol., 2002, $315,239-251$.

[130] Samuni, U.; Juszczak, L.; Dantsker, D.; Khan, I.; Friedman, A.J.; PerezGonzalez-de-Apodaca, J.; Bruno, S.; Hui, H.L.; Colby, J.E.; Karasik, E.; Kwiatkowski, L.D.; Mozzarelli, A.; Noble, R.; Friedman, J.M. Functional and spectroscopic characterization of half-liganded iron-zinc hybrid hemoglobin: Evidence for conformational plasticity within the $\mathrm{T}$ state. Biochem., 2003, 42, 8272-8288.

[131] Sottini, S.; Abbruzzetti, S.; Spyrakis, F.; Bettati, S.; Ronda, L.; Mozzarelli, A.; Viappiani, C. Geminate rebinding in R state hemoglobin: Kinetic and computational evidence for multiple hydrophobic pockets. J. Am. Chem Soc., 2005, 127, 17427-17432.

[132] Sottini, S.; Viappiani, C.; Ronda, L.; Bettati, S.; Mozzarelli, A. Co rebinding kinetics to myoglobin- and $\mathrm{R}$ state hemoglobin- doped silica gels in the presence of glycerol. J. Phys. Chem. B, 2004, 108, 8475-8484.

[133] Samuni, U.; Dantsker, D.; Roche, C.J.; Friedman, J.M. Ligand recombination and a hierarchy of solvent slaved dynamics: The origin of kinetic phases in hemeproteins. Gene, 2007, 398, 234-248.

[134] Samuni, U.; Roche, C.J.; Dantsker, D.; Friedman, J.M. Conformational dependence of hemoglobin reactivity under high viscosity conditions: The role of solvent slaved dynamics. J. Am. Chem. Soc., 2007, 129, 12756-12764.

[135] Eaton, W.A.; Henry, E.R.; Hofrichter, J.; Bettati, S.; Viappiani, C.; Mozzarelli, A. Evolution of allosteric models for hemoglobin. IUBMB Life, 2007, 59, 586-599.

[136] Jones, P.; Binns, D.; Chang, H.Y.; Fraser, M.; Li, W.; McAnulla, C McWilliam, H.; Maslen, J.; Mitchell, A.; Nuka, G.; Pesseat, S.; Quinn, A.F.; Sangrador-Vegas, A.; Scheremetjew, M.; Yong, S.Y.; Lopez, R.; Hunter, S. Interproscan 5: Genome-scale protein function classification. Bioinformatics, 2014, 30(9), 1236-1240.

[137] Abbruzzetti, S.; Bruno, S.; Faggiano, S.; Grandi, E.; Mozzarelli, A.; Viappiani, C. Time-resolved methods in biophysics. 2. Monitoring haem proteins at work with nanosecond laser flash photolysis. Photochem. Photobiol. Sci., 2006, 5, 1109-1120.

[138] Abbruzzetti, S.; Spyrakis, F.; Bidon-Chanal, A.; Luque, F.J.; Viappiani, C. Ligand migration through hemeprotein cavities: Insights from laser flash photolysis and molecular dynamics simulations. Phys. Chem. Chem. Phys., 2013, 15, 10686-10701.

[139] Abbruzzetti, S.; Viappiani, C.; Bruno, S.; Mozzarelli, A. Enhanced geminate ligand rebinding upon photo-dissociation of silica gel-embedded myoglobinco. Chem. Phys. Lett., 2001, 346, 430-436.

[140] Samuni, U.; Dantsker, D.; Ray, A.; Wittenberg, J.B.; Wittenberg, B.A.; Dewilde, S.; Moens, L.; Ouellet, Y.; Guertin, M.; Friedman, J.M. Kinetic modulation in carbonmonoxy derivatives of truncated hemoglobins. The role of distal heme pocket residues and extended apolar tunnel. J. Biol. Chem. 2003, 278, 27241-27250.

[141] Hargrove, M.S. A flash photolysis method to characterize hexacoordinate hemoglobin kinetics. Biophys. J., 2000, 79, 2733-2738.

[142] Hoy, J.A.; Hargrove, M.S. The structure and function of plant hemoglobins. Plant Physiol. Biochem., 2008, 46, 371-379.

[143] Burmester, T.; Weich, B.; Reinhardt, S.; Hankeln, T. A vertebrate globin expressed in the brain. Nature, 2000, 407, 520-523.

[144] Dewilde, S.; Kiger, L.; Burmester, T.; Hankeln, T.; Baudin-Creuza, V.; Aerts, T.; Marden, M.C.; Caubergs, R.; Moens, L. Biochemical characterization and ligand binding properties of neuroglobin, a novel member of the globin family. J. Biol. Chem., 2001, 276, 38949-38955.

[145] Burmester, T.; Ebner, B.; Weich, B.; Hankeln, T. Cytoglobin: A novel globin type ubiquitously expressed in vertebrate tissues. Mol. Biol. Evol., 2002, 19, 416-421.

[146] Lechauve, C.; Chauvierre, C.; Dewilde, S.; Moens, L.; Green, B.N.; Marden, M.C.; Celier, C.; Kiger, L. Cytoglobin conformations and disulfide bond formation. FEBS J., 2010, 277, 2696-2704. 
[147] Kakar, S.; Hoffman, F.G.; Storz, J.F.; Fabian, M.; Hargrove, M.S. Structure and reactivity of hexacoordinate hemoglobins. Biophys. Chem., 2010, 152, 114.

[148] Bruno, S.; Faggiano, S.; Spyrakis, F.; Mozzarelli, A.; Abbruzzetti, S.; Grandi, E.; Viappiani, C.; Feis, A.; Mackowiak, S.; Smulevich, G.; Cacciatori, E.; Dominici, P. The reactivity with co of ahb1 and ahb2 from arabidopsis thaliana is controlled by the distal His E7 and internal hydrophobic cavities. J. Am. Chem. Soc., 2007, 129, 2880-2889.

[149] Abbruzzetti, S.; Grandi, E.; Bruno, S.; Faggiano, S.; Spyrakis, F.; Mozzarelli, A.; Dominici, P.; Viappiani, C. Ligand migration in non symbiotic hemoglobin AHb1 from Arabidopsis thaliana. J. Phys. Chem. B, 2007, 111, 12582-12590.

[150] Faggiano, S.; Abbruzzetti, S.; Spyrakis, F.; Grandi, E.; Viappiani, C.; Bruno, S.; Mozzarelli, A.; Cozzini, P.; Astegno, A.; Dominici, P.; Brogioni, S.; Feis, A.; Smulevich, G.; Carrillo, O.; Schmidtke, P.; Bidon-Chanal, A.; Luque, F.J. Structural plasticity and functional implications of internal cavities in distal mutants of type 1 non-symbiotic hemoglobin AHb1 from Arabidopsis thaliana. J. Phys. Chem. B, 2009, 113, 16028-16038.

[151] Spyrakis, F.; Faggiano, S.; Abbruzzetti, S.; Dominici, P.; Cacciatori, E.; Astegno, A.; Droghetti, E.; Feis, A.; Smulevich, G.; Bruno, S.; Mozzarelli, A.; Cozzini, P.; Viappiani, C.; Bidon-Chanal, A.; Luque, F.J. Histidine E7 dynamics modulates ligand exchange between distal pocket and solvent in AHb1 from Arabidopsis thaliana. J. Phys. Chem. B, 2011, 115, 4138-4146.

[152] Bruno, S.; Faggiano, S.; Spyrakis, F.; Mozzarelli, A.; Cacciatori, E.; Dominici, P.; Grandi, E.; Abbruzzetti, S.; Viappiani, C. Different roles of protein dynamics and ligand migration in non-symbiotic hemoglobins AHb1 and AHb2 from Arabidopsis thaliana. Gene, 2007, 398, 224-233.

[153] Bisht, N.K.; Abbruzzetti, S.; Uppal, S.; Bruno, S.; Spyrakis, F.; Mozzarelli, A.; Viappiani, C.; Kundu, S. Ligand migration and hexacoordination in type 1 non symbiotic rice hemoglobin. BBA Proteins Proteom., 2011, 1814, 10421053 .

[154] Spyrakis, F.; Luque, F.J.; Viappiani, C. Structural analysis in nonsymbiotic hemoglobins: What can we learn from inner cavities? Plant Sci., 2011, 181, 8-13.

[155] Kriegl, J.M.; Bhattacharyya, A.J.; Nienhaus, K.; Deng, P.; Minkow, O.; Nienhaus, G.U. Ligand binding and protein dynamics in neuroglobin. Proc. Natl. Acad. Sci. U.S.A., 2002, 99, 7992-7997.

[156] Nienhaus, K.; Kriegl, J.M.; Nienhaus, G.U. Structural dynamics in the active site of murine neuroglobin and its effects on ligand binding. J. Biol. Chem., 2004, 279, 22944-22952.

[157] Kiger, L.; Uzan, J.; Dewilde, S.; Burmester, T.; Hankeln, T.; Moens, L.; Hamdane, D.; Baudin-Creuza, V.; Marden, M.C. Neuroglobin ligand binding kinetics. IUBMB Life, 2004, 56, 709-719.

[158] Uzan, J.; Dewilde, S.; Burmester, T.; Hankeln, T.; Moens, L.; Hamdane, D.; Marden, M.C.; Kiger, L. Neuroglobin and other hexacoordinated hemoglobins show a weak temperature dependence of oxygen binding. Biophys. J., 2004, 87, 1196-1204.

[159] Abbruzzetti, S.; Faggiano, S.; Bruno, S.; Spyrakis, F.; Mozzarelli, A.; Dewilde, S.; Moens, L.; Viappiani, C. Ligand migration through the internal hydrophobic cavities in human neuroglobin. Proc. Natl. Acad. Sci. U.S.A., 2009, 106(45), 18984-18989.

[160] Brunori, M. Nitric oxide moves myoglobin centre stage. Trends Biochem. Sci., 2001, 26, 209-210.

[161] Brunori, M.; Giuffre, A.; Nienhaus, K.; Nienhaus, G.U.; Scandurra, F.M.; Vallone, B. Neuroglobin, nitric oxide, and oxygen: Functional pathways and conformational changes. Proc. Natl. Acad. Sci. U.S.A., 2005, 102, 84838488

[162] Gabba, M.; Abbruzzetti, S.; Spyrakis, F.; Bruno, S.; Mozzarelli, A.; Luque, F.J.; Viappiani, C.; Cozzini, P.; Nardini, M.; Germani, F.; Bolognesi, M.; Moens, L.; Dewilde, S. Co rebinding kinetics and molecular dynamics simulations highlight dynamic regulation of internal cavities in human cytoglobin. PLOS ONE, 2013, 8, e49770.

[163] Narang, U.; Jordan, J.D.; Bright, F.V.; Prasad, P.N. Probing the cybotactic region of prodan in tetramethyl orthosilicate-derived sol-gels. J. Phys. Chem., 1994, 98, 8101-8107.

[164] Cupane, A.; Levantino, M.; Santangelo, M.G. Near-infrared spectra of water confined in silica hydrogels in the temperature interval $365-5 \mathrm{k}$. J. Phys. Chem. B, 2002, 106, 11323-11328.

[165] Howells, A.R.; Zambrano, P.J.; Collinson, M.M. Diffusion of redox probes in hydrated sol-gel-derived glasses. Anal. Chem., 2000, 72(21), 5265-5271.

[166] Crupi, V.; Dianoux, A.J.; Majolino, D.; Migliardo, P.; Venuti, V. Dynamical response of liquid water in confined geometry by laser and neutron spectroscopies. Phys. Chem. Chem. Phys., 2002, 4(12), 2768-2773.

[167] Cammarata, M.; Levantino, M.; Cupane, A.; Longo, A.; Martorana, A.; Bruni, F. Structure and dynamics of water confined in silica hydrogels: X-ray scattering and dielectric spectroscopy studies. Eur. Phys. J. E Soft Matter., 2003, 12, S63-S66.

[168] Santangelo, M.G.; Levantino, M.; Cupane, A.; Jeschke, G. Solvation of a probe molecule by fluid supercooled water in a hydrogel at $200 \mathrm{~K}$. J. Phys. Chem. B, 2008, 112(49), 15546-15553.

[169] Schiro, G.; Cupane, A.; Vitrano, E.; Bruni, F. Dielectric relaxations in confined hydrated myoglobin. J. Phys. Chem. B, 2009, 113(28), 9606-9613.

[170] Gottfried, D.S.; Kagan, A.; Hoffman, B.M.; Friedman, J.M. Impeded rotation of a protein in a sol-gel matrix. J. Phys. Chem. B, 1999, 103, 2803-2807.
[171] Kramers, H.A. Brownian motion in a field of force and the diffusion model of chemical reactions. Physica, 1940, 7, 284-304

[172] Ansari, A.; Jones, C.M.; Henry, E.R.; Hofrichter, J.; Eaton, W. The role of solvent viscosity in the dynamics of protein conformational changes. Science, 1992, 256, 1796-1798.

[173] Frauenfelder, H.; Fenimore, P.W.; McMahon, B.H. Hydration, slaving and protein function. Biophys. Chem., 2002, 98, 35-48

[174] Massari, A.M.; Finkelstein, I.K.; Fayer, M.D. Dynamics of proteins encapsulated in silica sol-gel glasses studied with IR vibrational echo spectroscopy. J. Am. Chem. Soc., 2006, 128, 3990-3997.

[175] Santangelo, M.G.; Levantino, M.; Vitrano, E.; Cupane, A. Ferricytochrome c encapsulated in silica hydrogels: Correlation between active site dynamics and solvent structure. Biophys. Chem., 2003, 103, 67-75.

[176] Schiro, G.; Sclafani, M.; Caronna, C.; Natali, F.; Plazanet, M.; Cupane, A. Dynamics of myoglobin in confinement: An elastic and quasi-elastic neutron scattering study. Chem. Phys., 2008, 345(2-3), 259-266.

[177] Schiro, G.; Sclafani, M.; Natali, F.; Cupane, A. Hydration dependen dynamics in sol-gel encapsulated myoglobin. Eur. Biophis. J. Biophy., 2008, 37(5), 543-549

[178] Soares, C.M.F.; Dos Santos, O.A.; Olivo, J.E.; De Castro, H.F.; De Moraes, F.F.; Zanin, G.M. Influence of the alkyl-substituted silane precursor on solgel encapsulated lipase activity. J. Mol. Catal. B: Enzym., 2004, 29(1-6), 6979.

[179] Barao, C.E.; De Paris, L.D.; Dantas, J.H.; Pereira, M.M.; Cardozo, L.; De Castro, H.F.; Zanin, G.M.; De Moraes, F.F.; Soares, C.M.F. Characterization of biocatalysts prepared with thermomyces lanuginosus lipase and different silica precursors, dried using aerogel and xerogel techniques. Appl. Biochem. Biotechnol., 2014, 172(1), 263-274.

[180] Ursoiu, A.; Paul, C.; Kurtan, T.; Peter, F. Sol-gel entrapped Candida antarctica lipase b - a biocatalyst with excellent stability for kinetic resolution of secondary alcohols. Molecules, 2012, 17(11), 13045-13061.

[181] Liu, J.; Bai, S.Y.; Jin, Q.R.; Zhong, H.; Li, C.; Yang, Q.H. Improved catalytic performance of lipase accommodated in the mesoporous silicas with polymer-modified microenvironment. Langmuir, 2012, 28(25), 9788-9796.

[182] Nguyen, D.T.; Smit, M.; Dunn, B.; Zink, J.I. Stabilization of creatine kinase encapsulated in silicate sol-gel materials and unusual temperature effects on its activity. Chem. Mater., 2002, 14, 4300-4306.

[183] Cruz-Aguado, J.A.; Chen, Y.; Zhang, Z.; Brook, M.A.; Brennan, J.D. Entrapment of src protein tyrosine kinase in sugar-modified silica. Anal. Chem., 2004, 76(14), 4182-4188.

[184] Frenkel-Mullerad, H.; Avnir, D. Sol-gel materials as efficient enzyme protectors: Preserving the activity of phosphatases under extreme $\mathrm{pH}$ conditions. J. Am. Chem. Soc., 2005, 127(22), 8077-8081.

[185] Pioselli, B.; Bettati, S.; Demidkina, T.V.; Zakomirdina, L.N.; Phillips, R.S. Mozzarelli, A. Tyrosine phenol-lyase and tryptophan indole-lyase encapsulated in wet nanoporous silica gels: Selective stabilization of tertiary conformations. Protein Sci., 2004, 13(4), 913-924.

[186] Pioselli, B.; Bettati, S.; Mozzarelli, A. Confinement and crowding effects on tryptophan synthase alpha 2 beta 2 complex. FEBS Lett., 2005, 579(10), 2197-2202.

[187] Phillips, R.S.; Demidkina, T.V.; Zakomirdina, L.N.; Bruno, S.; Ronda, L.; Mozzarelli, A. Crystals of tryptophan indole-lyase and tyrosine phenol-lyase form stable quinonoid complexes. J. Biol. Chem., 2002, 277(24), 2159221597.

[188] Walcarius, A. Analytical applications of silica-modified electrodes - a comprehensive review. Electroanalysis, 1998, 10(18), 1217-1235.

[189] Carrasquilla, C.; Brennan, J.D. Functional nucleic acid entrapment in sol-gel derived materials. Methods, 2013, 63(3), 255-265.

[190] Habibi, B.; Jahanbakhshi, M.; Direct electrochemistry of hemoglobin in renewable mesoporous carbon ceramic electrode: A new kind of hydrogen peroxide biosensor. Microchim. Acta, 2015, 182(5-6), 957-963.

[191] Pisoschi, A.M. Biosensors as bio-based materials in chemical analysis: A review. J. Biobased Mater. Bio., 2013, 7(1), 19-38.

[192] Aurobind, S.V.; Amirthalingam, K.P.; Gomathi, H. Sol-gel based surface modification of electrodes for electro analysis. Adv. Colloid Interface Sci. 2006, 12l(1-3), 1-7.

[193] Pohanka, M. Biosensors containing acetylcholinesterase and butyrylcholinesterase as recognition tools for detection of various compounds. Chem. Pap., 2015, 69(1), 4-16.

[194] Salinas-Castillo, A.; Pastor, I.; Mallavia, R.; Mateo, C.R. Immobilization of a trienzymatic system in a sol-gel matrix: A new fluorescent biosensor for xanthine. Biosens. Bioelectron., 2008, 24(4), 1059-1062.

[195] Radin, S.; El-Bassyouni, G.; Vresilovic, E.J.; Schepers, E.; Ducheyne, P. In vivo tissue response to resorbable silica xerogels as controlled-release materials. Biomaterials, 2005, 26(9), 1043-1052.

[196] Mansur, H.S.; Orefice, R.L.; Vasconcelos, W.L.; Lobato, Z.P.; Machado, L.J. Biomaterial with chemically engineered surface for protein immobilization. J. Mater. Sci. Mater. Med., 2005, 16(4), 333-340.

[197] Vasylieva, N.; Marinesco, S. Enzyme immobilization on microelectrode biosensors. In: Neuromethods; 2013; Vol. 80, pp. 95-114.

[198] Collinson, M.M. Imprinted functionalized silica. In: The supramolecular chemistry of organic-inorganic hybrid materials; 2010; pp. 581-598.

[199] Wang, J.; Bowie, D.; Zhang, X.; Filipe, C.; Pelton, R.; Brennan, J.D. Morphology and entrapped enzyme performance in inkjet-printed sol-gel coatings on paper. Chem. Mater., 2014, 26(5), 1941-1947. 
[200] Jerónimo, P.C.A.; Araújo, A.N.; Montenegro, M.C.B.S.M.; Satinský, D.; Solich, P. Flow-through sol-gel optical biosensor for the colorimetric determination of acetazolamide. Analyst, 2005, 130, 1190-1197.

[201] Tsai, H.C.; Doong, R.A. Simultaneous determination of $\mathrm{pH}$, urea, acetylcholine and heavy metals using array-based enzymatic optical biosensor. Biosens. Bioelectron., 2005, 20(9), 1796-1804.

[202] Cruz-Aguado, J.A; Chen, Y; Zhang, Z; Elowe, N.H.; Brook, M.A; Brennan, J.D. Ultrasensitive ATP detection using firefly luciferase entrapped in sugar-modified sol-gel-derived silica. J. Am. Chem. Soc., 2004, 126(22), 6878-6879.

[203] Wang, C.; Huang, C.Y.C.; Lin, W.C. Optical ATP biosensor for extracellular atp measurement. Biosens. Bioelectron., 2013, 43(1), 355-361.

[204] Suwansa-ard, S.; Kanatharana, P.; Asawatreratanakul, P.; Limsakul, C.; Wongkittisuksa, B.; Thavarungkul, P. Semi disposable reactor biosensors for detecting carbamate pesticides in water. Biosens. Bioelectron., 2005, 21(3), 445-454.

[205] Singh, S.; Jain, D.V.S.; Singla, M.L. Sol-gel based composite of gold nanoparticles as matix for tyrosinase for amperometric catechol biosensor. Sens. Actuators, B, 2013, 182, 161-169.

[206] Raghu, P.; Reddy, T.M.; Gopal, P.; Reddaiah, K.; Sreedhar, N.Y. A novel horseradish peroxidase biosensor towards the detection of dopamine: A voltammetric study. Enzyme Microb. Technol., 2014, 57, 8-15.

[207] Hussain, F.; Birch, D.J.; Pickup, J.C. Glucose sensing based on the intrinsic fluorescence of sol-gel immobilized yeast hexokinase. Anal. Biochem., 2005, $339(1), 137-143$

[208] Albanese, D.; Sannini, A.; Malvano, F.; Pilloton, R.; Di Matteo, M. Optimisation of glucose biosensors based on sol-gel entrapment and prussian blue-modified screen-printed electrodes for real food analysis. Food Anal. Method., 2014, 7(5), 1002-1008.

[209] Lin, T.Y.; Wu, C.H.; Brennan, J.D. Entrapment of horseradish peroxidase in sugar-modified silica monoliths: Toward the development of a biocatalytic sensor. Biosens. Bioelectron., 2007, 22(9-10), 1861-1867.

[210] Xu, S.X.; Li, J.L.; Zhou, Z.L.; Zhang, C.X. A third-generation hydrogen peroxide biosensor based on horseradish peroxidase immobilized by sol-gel thin film on a multi-wall carbon nanotube modified electrode Anal. Methods, 2014, 6(16), 6310-6315.

[211] Di, J.; Cheng, J.; Xu, Q.; Zheng, H.; Zhuang, J.; Sun, Y.; Wang, K.; Mo, X. $\mathrm{Bi}, \mathrm{S}$. Direct electrochemistry of lactate dehydrogenase immobilized on silica sol-gel modified gold electrode and its application. Biosens. Bioelectron., 2007, 23(5), 682-687.

[212] Campas, M.; Szydlowska, D.; Trojanowicz, M.; Marty, J.L. Towards the protein phosphatase-based biosensor for microcystin detection. Biosens. Bioelectron., 2005, 20(8), 1520-1530.

[213] Raghu, P.; Mohan Reddy, M.; Madhusudana Reddy, T.; Kumara Swamy, B.E.; Reddaiah, K. Development of sol-gel immobilized electrochemical biosensor for the monitoring of organophosphorous pesticides: A voltammetric method. Anal. Bioanal. Electrochem., 2013, 5(2), 139-153.

[214] Monton, M.R.; Lebert, J.M.; Little, J.R.; Nair, J.J.; McNulty, J.; Brennan, J.D. A sol-gel-derived acetylcholinesterase microarray for nanovolume small-molecule screening. Anal. Chem., 2010, 82(22), 9365-9373.

[215] Perullini, M.; Ferro, Y.; Durrieu, C.; Jobbagy, M.; Bilmes, S.A. Sol-gel silica platforms for microalgae-based optical biosensors. J. Biotechnol., 2014, 179, 65-70

[216] Di, J.; Peng, S.; Shen, C.; Gao, Y.; Tu, Y. One-step method embedding superoxide dismutase and gold nanoparticles in silica sol-gel network in the presence of cysteine for construction of third-generation biosensor. Biosens. Bioelectron., 2007, 23(1), 88-94.

[217] Hui, C.Y.; Li, Y.; Brennan, J.D. Fluorescence analysis of the properties of structure-switching DNA aptamers entrapped in sol-gel-derived silica materials. Chem. Mater., 2014, 26(5), 1896-1904.

[218] Mozzarelli, A.; Rivetti, C.; Rossi, G.L.; Eaton, W.A.; Henry, E.R. Allosteric effectors do not alter the oxygen affinity of hemoglobin crystals. Protein Sci., 1997, 6(2), 484-489.

[219] Mozzarelli, A.; Rivetti, C.; Rossi, G.L.; Henry, E.R.; Eaton, W.A. Crystals of hemoglobin with the t-quarternary structure bind oxygen noncooperatively with no bohr effect. Nature, 1991, 351(6325), 416-419. 